Nr. 251 | 17.05.2021

Ukraine-Analysen

- Außenpolitik

- Beziehungen Ukraine-Türkei

- Donbas

ANALYSE

Ukrainische Außenpolitik unter Selenskyj: Von Wirtschaft zu Sicherheit

Von Susan Stewart (Stiftung Wissenschaft und Politik, Berlin)

ANALYSE

Türkei-Ukraine Beziehungen: Was steckt dahinter?

Von Daria Isachenko (Stiftung Wissenschaft und Politik, Berlin)

STATISTIK

Handelsbeziehungen zwischen der Ukraine und der Türkei

ANALYSE

Krieg und Frieden im Donbas: Lehren aus dem russischen Truppenaufmarsch 11

Von Jakob Hauter (University College London)

STATISTIK

Konflikt im Donbas

DEKODER

Vom Säbelrasseln zum Krieg?

Von Fjodor Krascheninnikow

STATISTIK

Die Verbreitung von Covid-19 in der Ukraine (Stand: 17. Mai 2021) 20

CHRONIK

Covid-19-Chronik, 26. April - 09. Mai 2021

CHRONIK

26. April - 09. Mai 2021

Deutsches

Polen-Institut 


\title{
Ukrainische Außenpolitik unter Selenskyj: Von Wirtschaft zu Sicherheit
}

\author{
Von Susan Stewart (Stiftung Wissenschaft und Politik, Berlin)
}

DOI: $10.31205 /$ UA.251.01

\section{Zusammenfassung}

Die ukrainische Außenpolitik hat derzeit eher einen ad hoc- als einen strategischen Charakter. Dennoch lässt sich eine gewisse Evolution feststellen, die von einem fast alleinigen Schwerpunkt auf dem Krieg im Donbas über eine Akzentuierung von Wirtschaftsaspekten hin zu einer klaren Betonung von Sicherheitsfragen geht. Geprägt wird die Außenpolitik v. a. durch den amtierenden Präsidenten Wolodymyr Selenskyj und dessen Team im Präsidentenbüro. In den kommenden Monaten wird die Situation im Schwarzmeerraum besondere Aufmerksamkeit erfordern. Hier wird es allerdings nicht nur auf die Ukraine ankommen, sondern auf ein sinnvolles Zusammenspiel zahlreicher staatlicher und multilateraler Akteure.

\section{Die Entstehung einer präsidial geprägten Außenpolitik}

Bei der Außenpolitik sieht die ukrainische Verfassung ein Zusammenspiel zwischen dem Parlament, dem Präsidenten und der Regierung vor. Sie legt fest, dass das Parlament die Prinzipien der Innen- und Außenpolitik definiert (Art. 85, Nr. 5), während der Präsident die außenpolitische Tätigkeit des Landes leitet (Art. 106, Nr. 3). Die Regierung ist für die Durchführung der Außenpolitik zuständig (Art. 116, Nr. 1). Während der Präsidentschaft von Wolodymyr Selenskyj ist das Präsidentenbüro (die frühere Präsidialadministration) für fast alle Politikbereiche zunehmend wichtig geworden, so auch für den Bereich der Außenpolitik. In einem Interview mit der ukrainischen Webseite lb.ua betonte der Vize-Leiter des Präsidentenbüros Ihor Schowkwa, dass die folgenden außenpolitischen Funktionen bei diesem Büro lägen: strategische Planung, Festlegung der Ziele, Sicherung der alltäglichen außenpolitischen Tätigkeit des Präsidenten. Akteure wie das Außenministerium setzten die Politik lediglich um. Auch wenn es hiervon Ausnahmen gibt, scheint dieses Schema der heutigen Praxis in der Ukraine weitgehend zu entsprechen und wird deswegen als Grundlage für diese Analyse angenommen. Die Betonung im Folgenden liegt deshalb auf dem Präsidenten und seinem Team. Andere Akteure kommen zwar vor, werden aber weniger einschlägig behandelt.

Während seines Wahlkampfes hat Wolodymyr Selenskyj kein außenpolitisches Programm präsentiert. Dies ist nicht sehr überraschend, da er als Politnovize keine politische und dadurch auch keine außenpolitische Erfahrung besaß. Dasselbe traf auch für die meisten Personen, die seinen Wahlkampf eng begleiteten, zu. Dennoch hatte eine der zentralen Botschaften seines Wahlkampfes mit mehreren Aspekten der Außenpolitik zu tun. Dies war das Versprechen, Frieden im Donbas durchzusetzen. Dabei sprach Selenskyj insbe- sondere von seiner Absicht, durch einen bilateralen Austausch mit dem russischen Präsidenten Wladimir Putin diese Frage zu regeln. Außerdem äußerte er Überlegungen, das seit 2014 bestehende Normandie-Format zu ersetzen bzw. durch andere Akteure (v. a. die USA und Großbritannien) zu erweitern. Diese Überlegungen waren aber keineswegs in ein breiteres außenpolitisches Konzept eingebettet.

\section{Investitionen gesucht! Eine Außenpolitik unter wirtschaftlichen Vorzeichen}

Es hat entsprechend gedauert, bis erste Leitlinien in der Außenpolitik unter Selenskyj sichtbar wurden. Diese sind auch eher informell, da eine außenpolitische Strategie noch nicht existiert - auch wenn sich eines in der Planung befindet. Was es jedoch gibt, ist die Nationale Sicherheitsstrategie, die im September 2020 erneuert wurde. Ihre Neuauflage geht mit einem Wandel in den außenpolitischen Prioritäten von Wirtschaft zu Sicherheit einher (s. u.).

In einer ersten Phase wurde ein starker Akzent auf wirtschaftliche Ziele gelegt. Selenskyj und seine Entourage haben entschieden, die Außenpolitik v. a. für die Erreichung ökonomischer Fortschritte zu nutzen, insbesondere um Investitionen in die Ukraine zu fördern. Nicht nur wurde die Tradition von regelmäßigen Wirtschaftsforen in Kyjiw sowie anderswo fortgesetzt, sondern es kamen neue Foren hinzu. Vor allem die Investment Conference in Mariupol im Oktober 2019 hat erhebliche Aufmerksamkeit auf sich gezogen und sollte das Interesse ausländischer Investor/innen für die Potenziale der Ostukraine wecken. Im Januar 2020 nutzte Selenskyj seine Rede auf dem prestigereichen Internationalen Wirtschaftsforum in Davos, um die Vorteile der Ukraine für ausländische Investor/innen aufzuführen. Allerdings haben diese Bemühungen kaum gefruchtet. Auch wenn man die Auswirkungen der Covid-19Pandemie in Betracht zieht, die vergangenes Jahr zu 
den niedrigsten ausländischen Direktinvestitionen seit Jahren geführt haben, sind es weiterhin allen voran die rechtsstaatlichen Mängel in der Ukraine, die Investor/ innen davon abhalten, aktiver zu werden.

Bei der Suche nach Investitionen kam eine Initiative des Außenministers Dmytro Kuleba hinzu, einen starken "asiatischen Vektor" in der ukrainischen Außenpolitik zu eröffnen. Er betonte den wachsenden Handel zwischen der Ukraine und vielen asiatischen Ländern und plädierte für dessen Weiterentwicklung sowie für gemeinsame Projekte im Bereich der Hochtechnologie und beim Ausbau der Infrastruktur. Dieser Vektor bekräftigte die ukrainische Absicht, ökonomische Anliegen in den Vordergrund zu stellen, denn andere Ziele waren und sind in den Beziehungen zu den asiatischen Staaten wenig realistisch.

Dieser Vektor sowie einige weitere Entwicklungen stellten die bisherigen Prioritäten der ukrainischen Außenpolitik zeitweilig infrage. Da die personellen und materiellen Ressourcen des außenpolitischen Apparats in der Ukraine sehr begrenzt sind, tauchte die Befürchtung auf, dass sich eine stärkere Ausrichtung auf den asiatischen Raum negativ auf das Verhältnis zur EU sowie zu den USA und zur NATO auswirken könnte. Das wurde bekräftigt durch einige Schritte im Rahmen des Normandie-Formats und der Trilateralen Kontaktgruppe, die die Bereitschaft der ukrainischen Seite (und konkret des Präsidentenbüros) suggerierten, Zugeständnisse gegenüber Russland zu machen, um Fortschritte bei der Umsetzung der Minsker Vereinbarungen zu erreichen.

Allerdings haben die Entwicklungen im Rahmen des Minsker Prozesses gezeigt, dass diese Zugeständnisse nicht zu entsprechenden Gegenschritten der russischen Seite geführt haben (siehe die Analyse zum Donbas in dieser Ausgabe). Wohl als Lehre aus dieser Erfahrung fing die ukrainische Seite an, vermehrt nach Sicherheitsgarantien bzw. zumindest nach militärischer Unterstützung von ihren außenpolitischen Partner/innen zu suchen. So erfolgte eine partielle Evolution der Akzente: von der Wirtschaft zur Sicherheit.

\section{Sicherheitsfragen nehmen immer mehr Raum ein}

Ein Indiz für diese Evolution war die Veröffentlichung einer neuen Version der Nationalen Sicherheitsstrategie der Ukraine im September 2020. Gekennzeichnet durch ein breites Verständnis von Sicherheit, bekräftigt das Dokument die westliche Ausrichtung der ukrainischen Außen- und Sicherheitspolitik, indem es die USA, das Vereinigte Königreich, Kanada, Deutschland und Frankreich als prioritäre Partner charakterisiert. Das sind auch diejenigen Länder, von denen die Ukraine am meisten einen Beitrag im Hinblick auf den russisch- ukrainischen Konflikt im Donbas erwartet. Die russische Aggression spielt eine wichtige Rolle in der Strategie, und die Ukraine erklärt ihre Absicht, die Kosten dieser Aggression für Russland durch eine Stärkung der ukrainischen Verteidigungskapazität sowie durch internationale Zusammenarbeit zu erhöhen.

Ein weiteres Zeichen für die wachsende Betonung auf Sicherheit ist die Schaffung der sog. Krim-Plattform, die insbesondere seit Ende 2020 an Dynamik gewonnen hat. Was die außenpolitische Komponente betrifft, geht es darum, internationale Unterstützung für die territoriale Integrität der Ukraine zu sichern und mit ausländischen Partner/innen auf eine Rückkehr der Halbinsel unter ukrainische Kontrolle hinzuwirken. Es handelt sich auch u. a. darum, andere Akteur/innen für die fortschreitende Militarisierung der Krim durch Russland und deren Implikationen für die Ukraine und den Schwarzmeerraum zu sensibilisieren.

Gute Beispiele für den fließenden Übergang von wirtschaftlichen zu sicherheitspolitischen Aspekten der Außenpolitik sind die Abkommen und Vereinbarungen, die die Ukraine mit dem Vereinigten Königreich (VK) sowie mit der Türkei abgeschlossen hat (siehe auch den Beitrag zum Verhältnis Ukraine-Türkei in dieser Ausgabe). Im Fall des VK ging es v. a. darum, das EU-Ukraine-Assoziierungsabkommen zu ersetzen, da es nach dem Brexit für das VK nicht mehr gilt. Hinzu kam ein wichtiges Memorandum, das der Ukraine einen Kredit über 1,25 Milliarden Pfund zu günstigen Bedingungen garantiert, um zusammen mit dem VK neue Schiffe für die ukrainische Flotte zu bauen. Mit der Türkei haben die sicherheitspolitischen Elemente der Partnerschaft bislang dominiert, auch wenn beide Seiten ein Freihandelsabkommen sowie einen Handelsumsatz von 10 Milliarden USD als Ziel angeben. Wichtiger in der aktuellen Lage ist allerdings, dass die Ukraine türkische Drohnen bereits erworben hat und dass beide Staaten sich schriftlich zu einer Vertiefung ihrer Zusammenarbeit im Verteidigungsbereich verpflichtet haben. Konkrete Kooperation in dieser Sphäre ist für die Ukraine in Anbetracht des sich fortsetzenden Konflikts mit Russland von erheblicher Bedeutung.

Auch die Beziehungen zu den unmittelbaren Nachbarn der Ukraine entwickelten sich z. T. im Zeichen des Donbas-Konflikts. Dies trifft insbesondere für Belarus zu, wo u. a. die zunehmende Abhängigkeit des illegitimen Präsidenten Aleksandr Lukashenka von Russland zu einem immer schlechteren Verhältnis mit der Ukraine führt. Aus diesem Grund ist die ukrainische Seite nicht mehr bereit, die regelmäßigen (derzeit wegen der Covid-19-Pandemie virtuellen) Treffen der Trilateralen Kontaktgruppe in Minsk abzuhalten und sucht entsprechend nach einem alternativen Ort für die postPandemie-Phase. Probleme im Verhältnis zu Polen (v. a. 
geschichtspolitische Fragen) sowie Ungarn (Umgang mit der ungarischen Minderheit) sind in letzter Zeit in den Hintergrund getreten angesichts eines potenziell drohenden russischen Angriffs. Die Beziehungen zur Republik Moldau sowie zu Georgien sind weniger intensiv als man das im Hinblick auf gewisse Ähnlichkeiten (z. B. dass alle drei Staaten Assoziierungsabkommen mit der EU umsetzen) erwarten würde. Im Falle Georgiens liegt das zum großen Teil daran, dass die Ukraine den ehemaligen georgischen Präsidenten Mikheil Saakaschwili beherbergt, der in Georgien zu mehreren Haftstrafen verurteilt wurde und sich weiterhin aus der Ferne in die georgische Innenpolitik einmischt.

\section{Das Verhältnis zu westlichen Akteuren im Zeichen der russischen Eskalation}

Das bilaterale Verhältnis zu den USA verdient besondere Aufmerksamkeit. Auch wenn die Jahre der TrumpPräsidentschaft weniger katastrophal ausgefallen sind wie in der Ukraine ursprünglich befürchtet, war die Erleichterung in Kyjiw über die Wahl von Joe Biden zum US-Präsidenten im November 2020 dennoch spürbar. Die Kombination von Bidens kritischer Haltung gegenüber Russland und seinen guten Kenntnissen der ukrainischen Entwicklung aus seiner Zeit als Vize-Präsident unter Barack Obama hat große - wohl überzogene - Erwartungen in der ukrainischen Elite geweckt. Diese betreffen v. a. das Ausmaß der US-amerikanischen Unterstützung im Hinblick auf die russische Bedrohung im Donbas, aber auch in anderen Bereichen. In Kyjiw wird oft ausgeblendet, wie viele andere Baustellen für die USA (sowie für die EU) relevant sind. Auch wird gern übersehen, dass Präsident Biden die Ukraine nicht nur als Opfer bzw. Objekt der russischen Aggression sieht, sondern auch als Subjekt, von dem erhebliche Leistungen in verschiedenen Reformbereichen erwartet werden, insbesondere was Rechtsstaatlichkeit und Korruptionsbekämpfung betrifft.

Dennoch lag der Akzent in den letzten Wochen verständlicherweise fast ausschließlich auf dem Aspekt der russischen Aggression. Insgesamt scheint der russische Aufmarsch an den Grenzen der Ostukraine sowie auf der illegal annektierten Halbinsel Krim und im Schwarzen Meer im März-April 2021 der Ukraine Recht zu geben bezüglich ihrer Betonung von Sicherheitsfragen in der Außenpolitik. Anfang März haben die USA militärische Unterstützung im Rahmen von 125 Millionen US-Dollar für die Ukraine beschlossen, und Ende April wurde ein Gesetz über weitere 300 Millionen US-Dollar (inkl. für letale Waffen) jährlich bis 2026 im Senat eingebracht. Allerdings hat die Ukraine ihr Verhältnis zum Westen mit der Forderung, die Frage der NATO-Mitgliedschaft jetzt anzugehen, überstrapaziert. Während einige Staaten diese Idee - oder zumindest die Verlei- hung eines Mitgliedschaftsaktionsplans, kurz MAP unterstützen (z. B. Litauen, die Türkei und vermutlich auch Polen), hat die Reaktion auf die ukrainische Forderung insgesamt gezeigt, dass es in der NATO hierfür keinen Konsens gibt.

In dieser Lage kommt die sicherheitspolitische Schwäche der EU deutlich zum Vorschein. Da sie der Ukraine im Vergleich zu den USA und zur NATO relativ wenig in dieser Sphäre zu bieten hat, tritt die EU für die Ukraine derzeit eher in den Hintergrund. Selbst wenn der französische Präsident Emmanuel Macron die Notwendigkeit unterstrich, rote Linien festzulegen und auch bereit sein zu müssen, bei ihrer Überschreitung zu reagieren, hat die EU weder Sanktionen noch weitere Schritte in Aussicht gestellt, sondern Russland lediglich zu einer Deeskalation durch den Abzug seiner Truppen aufgerufen. Sicherlich hat die EU mehr auf der wirtschaftlichen Schiene zu bieten, aber auch hier versucht die Ukraine, auf Änderungen im Assoziierungsabkommen hinzuwirken, um z. B. höhere Exportquoten für ukrainische Produkte in die EU zu erreichen. Hiermit war sie in der Vergangenheit teilweise erfolgreich. Jetzt steht die Ukraine wohl relativ kurz vor dem Abschluss eines Agreement on Conformity Assessment and Acceptance of Industrial Products (ACAA). Damit wird sie Produkte in einzelnen Sektoren ohne langwierige und komplexe Überprüfungen in die EU exportieren dürfen. Das wäre ein wichtiger Schritt bei der Integration in den Binnenmarkt, unterstreicht aber gleichzeitig den hauptsächlich zweckmäßig-wirtschaftlichen Charakter der Zusammenarbeit.

Deutschland hat in den letzten Jahren ein enges Verhältnis zur Ukraine gepflegt, nicht nur aufgrund der deutschen Beteiligung am Normandie-Format, sondern auch durch erhebliche Unterstützung für zahlreiche Reformprozesse. Dennoch ist mit dem Schwenk zu einer größeren Betonung auf Sicherheitsfragen eine wachsende Enttäuschung bei vielen ukrainischen Akteuren bezüglich der deutschen Rolle entstanden. Dies hat sich v. a. in den letzten Monaten während des russischen Aufmarsches gezeigt. Insbesondere, weil Deutschland 2014 eine überraschend starke Rolle gespielt und seitdem Sanktionen gegen Russland im EU-Rahmen mitgesichert hat, waren die Erwartungen an Berlin hoch. Eine deutliche Frustration mit dem deutschen Festhalten am Nord Stream 2-Projekt setzt sich hinsichtlich der neuesten Entwicklungen fort. Es gibt aber auch wenig Verständnis für die Tendenz einiger deutscher Akteure, auch die Ukraine für das Ausbleiben von Fortschritten im Minsker Prozess zu beschuldigen, sowie für den hartnäckigen Kooperationsdiskurs in Deutschland vis-à-vis Russland, der selbst angesichts einer einseitigen militärischen Eskalation durch die russischen Streitkräfte anhält. 


\section{Fazit: Sicherheit wird Wirtschaft weiterhin trumpfen}

Die Naivität, mit der Wolodymyr Selenskyj ursprünglich an das Donbas-Problem herangegangen ist, ist mittlerweile verflogen. Sein Verständnis für die Schwierigkeiten, die mit internen Reformprozessen einhergehen, hat sich gleichzeitig vertieft. Von daher wird in Bezug auf die russische Aggression eine härtere Linie vertreten, und während die Suche nach Investitionen weitergeht, steht sie nicht mehr so stark im Mittelpunkt der Außenpolitik. Stattdessen wird nach sicherheitspolitischer Unterstützung gesucht, was ein intensiveres Ver- hältnis zu vielen westlichen Akteuren erfordert. Der russische Aufmarsch der letzten Wochen hat gezeigt, dass Sicherheitsfragen für die Ukraine weiterhin höchste Priorität genießen werden. In diesem Zusammenhang wird die Entwicklung im Schwarzmeerraum für die kommenden Monate wohl von großer Bedeutung sein. Dies wird eine komplexe Vorgehensweise verlangen und intensive Gespräche mit den einzelnen Anrainerstaaten aber auch mit der EU und der NATO sowie mit den USA notwendig machen, um der wachsenden russischen Dominanz in diesem Raum gezielt und effektiv entgegenzutreten.

\section{Über die Autorin}

Dr. Susan Stewart ist Leiterin (a. i.) der Forschungsgruppe Osteuropa und Eurasien an der Stiftung Wissenschaft und Politik in Berlin.

\section{Lesetipps/Bibliographie}

- Centre for Defence Strategies. Ukrainian Storm Warning: A Grave Danger to Europe in the Maritime Domain, November 2020, https://defence.org.ua/wp-content/uploads/2020/12/CDS_Maritime-Security-Report_2020.pdf

- Oleksiy Honcharuk, Roman Waschuk. "How Ukraine Lost Its Investment Paradise«, The National Interest, 9. April 2021, https://nationalinterest.org/feature/how-ukraine-lost-its-investment-paradise-182332

- Dmytro Kuleba. »Ukraine’s Road to Asia: Ukraine will prioritize the Asia-Pacific in its foreign policy«, The Diplomat, 30. April 2020, https://thediplomat.com/2020/04/ukraines-road-to-asia/

- Steven Pifer. NATO's Ukraine Challenge: Ukrainians Want Membership, but Obstacles Abound, Brookings Institution, 6. Juni 2019, https://www.brookings.edu/blog/order-from-chaos/2019/06/06/natos-ukraine-challenge/

- Ihor Schowkwa. "SshA ne dadut nikomu beskarno rospotschaty nowi ahresywni diji u naschomu regioni« (»Die USA werden niemandem neue aggressive Handlungen in unserer Region unbestraft beginnen lassen«), lb.ua, 9. April 2021, https://lb.ua/world/2021/04/09/481939_igor_zhovkva_ssha_dadut_nikomu.html

- Maryna Shevtsova. Ukraine: Who is Who on Bankova Street? Unblurring the President's Administration Two Years after the Elections, 2021, https://violavoncramon.files.wordpress.com/2021/03/who-is-who-on-bankovastreet_greens_viola-von-cramon.pdf

- Ukrainian Prism. „B- despite the Pandemic: Ukraine’s Foreign Policy Scores 2020«, http://prismua.org/en/ scorecards 2020 . 


\section{Türkei-Ukraine Beziehungen: Was steckt dahinter?}

Von Daria Isachenko (Stiftung Wissenschaft und Politik, Berlin)

DOI: $10.31205 /$ UA.251.02

\section{Zusammenfassung}

Die ukrainische Führung setzt große Hoffnungen in die Türkei und sieht Ankara als einen strategischen Partner. Die Türkei soll Kyjiw dabei helfen, die ukrainische territoriale Integrität wiederherzustellen und gleichzeitig der NATO beizutreten. Der Handlungsspielraum Ankaras für konkrete Schritte, die über die solidarische Rhetorik hinausgehen, ist allerdings begrenzt. Das Hauptinteresse der Türkei bei der Zusammenarbeit mit Kyjiw liegt vielmehr darin, die Lücken in seiner Verteidigungsindustrie mit der ukrainischen Unterstützung zu füllen.

\section{Einleitung}

Im September 2020 hat die Ukraine in ihrer neuen Nationalen Sicherheitsstrategie neben Aserbaidschan, Georgien, Litauen und Polen auch die Türkei als einen strategischen Partner Kyjiws ausgezeichnet. In der letzten Zeit nähern sich die Türkei und die Ukraine in der Tat überraschend rasch an. Im Februar 2020 hat die Türkei den ukrainischen Streitkräften 36 Millionen USDollar Militärhilfen zugesagt. Im Oktober 2020 haben Ankara und Kyjiw ein Abkommen zur militärischen Zusammenarbeit unterzeichnet. Im April 2021 fand bereits das dritte Treffen zwischen dem ukrainischen Präsidenten Wolodymyr Selenskyj und seinem türkischen Amtskollegen Recep Tayyip Erdoğan seit dem Herbst letzten Jahres statt. Die gemeinsame Erklärung nach dem Treffen umfasste zwanzig Punkte. Im bilateralen Bereich wird eine Vertiefung im Handel und in Rüstungs- und Verteidigungsindustrien angestrebt. Die Ukraine setzt aber vor allem auf die Unterstützung der Türkei, um die ukrainische territoriale Integrität wieder etablieren zu können. Außerdem rechnet die Ukraine mit dem Engagement der Türkei bei den Bemühungen Kyjiws um eine NATO-Mitgliedschaft.

Die jüngste türkisch-ukrainische Annäherung findet vor dem Hintergrund einer zunehmend aktiven Rolle Ankaras im post-sowjetischen Raum statt. Im Herbst 2020 stellte sich die Türkei offensiv auf die Seite Aserbaidschans bei der militärischen Eskalation im Konflikt um Bergkarabach im Südkaukasus. Auch von einer Rückkehr der Türkei nach Zentralasien ist bereits die Rede. Für Ankara ist die Aussicht auf die Schaffung des Nachitschewan-Korridors, der die Türkei durch die aserbaidschanische Exklave Nachitschewan in Armenien mit Aserbaidschan verbinden soll, einer der Erfolge des Krieges zwischen Armenien und Aserbaidschan, da er dem Land einen Zugang zur Kaspischen Region und zu Zentralasien ermöglicht. Der Aktivismus Ankaras im post-sowjetischen Raum wird als Anzeichen der erneuten geopolitischen Rivalität mit Moskau gesehen. Die Beziehungen der Türkei zur Ukraine stechen in dieser Hinsicht besonders hervor, da das Schwarze Meer als ein Gebiet angesehen wird, in dem die Türkei ihre NATO-Position unter Beweis stellen kann, da sie in anderen Regionen wie im Nahen Osten und im östlichen Mittelmeerraum wie nie zuvor in die Kritik geraten ist. Doch ist die Türkei in der Lage den Erwartungen Kyjiws und ihrer NATOPartner im Kampf gegen Russland nachzukommen?

\section{Bilaterale Schwerpunkte: Drohnen, Handel und die Krim}

Kyjiw ist kein neuer Partner Ankaras. Schon 2011 etablierte die Türkei mit der Ukraine einen High-Levelstrategischen Rat (HLSR). Solche Räte hat die Türkei seit 2006 eingeführt, um mit ausgewählten Ländern die Zusammenarbeit institutionell zu vertiefen. Daneben haben die Türkei und die Ukraine kürzlich noch ein zusätzliches »Quadriga Format« eingeführt, im Rahmen dessen sich die Vertreter der ukrainischen und türkischen Ministerien für Auswärtiges und Verteidigung treffen, um sicherheitspolitische Fragen der Schwarzmeerregion zu besprechen. Im bilateralen Bereich haben sich in der letzten Zeit drei Kernpunkte der türkisichukrainischen Zusammenarbeit herauskristallisiert.

Erstens bildet die Sphäre des militärisch-industriellen Komplexes einen vielversprechenden Bereich für die Kooperation zwischen der Türkei und der Ukraine, da sie einen hohen Grad an Konvergenz aufweist. Die Türkei und die Ukraine haben u. a. ein gemeinsames Interesse an unbemannten Luftfahrzeugen, Triebwerken für gepanzerte Fahrzeuge, Turbinen, Flugzeugtriebwerken, Raketen und Schiffsbau. Medienberichten zufolge plant die Türkei für ihren Kampfhubschrauber Atak 2 ein in der Ukraine produziertes Triebwerk zu nutzen. Für die ukrainische Marine ist die Produktion der türkischen Korvetten (Ada-Klasse) vorgesehen. Die Ukraine hat bereits sechs Drohnen vom Typ Bayraktar TB2 und drei Bodenkontrollstationssysteme von der Türkei gekauft. Des Weiteren ist die Ukraine an Kauf bzw. Ko-Produktion von insgesamt 48 unbemannten Luftfahrzeugen interessiert. Gewünscht ist auch die Grün- 
dung gemeinsamer Unternehmen für die Produktion. Im Gespräch ist derzeit der Verkauf von rund 50 Prozent der Anteile vom führenden Motorenhersteller für Raketen, Flugzeuge und Hubscharuber, Motor Sitsch, an ein türkisches Unternehmen mit staatlicher Beteiligung. Im Januar 2021 hat die Ukraine den Verkauf von Motor Sitsch an das chinesische Luftfahrtunternehmen Skyrizon wegen Sanktionen seitens der USA abgebrochen. Die türkische Seite ist optimistisch, dass die von den USA gegen die Türkei verhängten Sanktionen keine Auswirkung auf die Zusammenarbeit mit der Ukraine im Rüstungs- und Verteidigungssektor haben werden.

Zweitens streben die Ukraine und die Türkei an, ein bilaterales Freihandelsabkommen abzuschließen. Im Vergleich zu den Fortschritten im Bereich des militärisch-industriellen Komplexes ist hier der Weg etwas holprig. Das Handelsvolumen von 2019 betrug 4,8 Milliarden US-Dollar, davon 2,09 Milliarden US-Dollar Exporte aus der Türkei und 2,72 Milliarden US-Dollar Importe aus der Ukraine. Mit dem Freihandelsabkommen soll sich das Handelsvolumen zwischen Kyjiw und Ankara auf 10 Milliarden US-Dollar verdoppeln. Das Abkommen sollte bereits im Februar 2020 unterschrieben werden, allerdings bestehen immer noch Uneinigkeiten. Diese umfassen unter anderem Quoten für Agrarprodukte sowie das Zertifizierungsverfahren in der Türkei. Auch das Investitionsklima in der Ukraine ist für türkische Unternehmen noch nicht attraktiv genug.

Drittens gibt es mit den Krimtataren wegen ihrer kulturellen und historischen Verwandtschaft mit den Turkvölkern ein besonderes Band in den ukrainisch-türkischen Beziehungen. Bereits nach dem Zerfall der Sowjetunion war die Türkei aktiv dabei, die Krimtataren in der Ukraine zu unterstützen. Die Türkische Agentur für Zusammenarbeit und Entwicklung (TIKA) hat für die Krimtataren, die Anfang der 1990er Jahre wieder in die Ukraine zurückkehrten, Wohn- und Kulturprojekte finanziert. Auch die Vereinbarung, die beim letzten Treffen zwischen Erdoğan und Selenskyj im April 2021 getroffen wurde, sieht türkische Hilfe für den Bau von 500 Häusern in den ukrainischen Städten Kyjiw, Mykolajiw und Cherson vor für Krimtataren, die 2014 die Halbinsel verlassen mussten. In der Türkei selbst wird die Diaspora der Krimtataren auf drei bis fünf Millionen Menschen geschätzt. Auch hat die Krim einen sehr bedeutsamen symbolischen Wert für die Türkei: Die Halbinsel war der erste territoriale Verlust für das Osmanische Reich im Jahr 1783.

\section{Regionale Zusammenhänge: Lehren aus 2014 und dem Konflikt um Bergkarabach} Seitens der Ukraine gibt es zwei besonders große Hoffnungen für die strategische Partnerschaft mit der Türkei. Erstens wünscht sich Kyjiw, dass Ankara sich stär- ker bei der "Krim-Plattform" engagiert, die Kyjiw im August $2021 \mathrm{zu}$ etablieren plant. Mit dieser Plattform bezweckt die Ukraine, internationale Aufmerksamkeit auf die Krim-Frage zu lenken, bzw. die Besetzung der Krim von Russland langfristig zu beenden. Dies soll unter anderem durch die Erarbeitung einer Nicht-Anerkennungs-Strategie für die Krim und durch die wirksame Umsetzung der Sanktionen gegenüber Russland erreicht werden. Zweitens setzt Kyjiw große Hoffnung auf Ankara auch bei der ukrainischen Bestrebung, einen Membership Action Plan (MAP) von der NATO zu bekommen, der die Ukraine zum formellen Antragsteller für eine NATO-Mitgliedschaft machen würde. Auch die Interoperabilität der ukrainischen Streitkräfte mit den NATO-Mitgliedern soll die Zusammenarbeit mit der Türkei fördern.

Die Türkei unterstützt zwar die Errichtung der KrimPlattform sowie Kyjiws Wunsch nach einer NATOMitgliedschaft, der Handlungsspielraum Ankaras für Schritte, die über die solidarische Rhetorik hinausgehen, bleibt allerdings stark eingeschränkt. Die Grenzen der türkischen Politik, insbesondere hinsichtlich der KrimFrage, wurden bereits 2014 deutlich.

Das "Referendum über den Status der Krim» am 16. März 2014 hat die Türkei zwar als rechtswidrig verurteilt. Für die Unterstützung der territorialen Integrität hat Ankara auch eigene Gründe. Referenden, die auf dem Selbstbestimmungsprinzip beruhen, sind für die Türkei problematisch, da Ankara die Auswirkungen auf seine eigene territoriale Integrität befürchtet. So hat die Türkei zwar der Resolution 68/262 der UN-Generalversammlung zur Ungültigkeit des Krim-Referendums im März 2014 zusammen mit 100 Ländern zugestimmt. Im Gegensatz zu westlichen Staaten hat sich die Türkei jedoch nicht an die Sanktionen gegenüber Russland angeschlossen. Bereits damals waren die Beziehungen zu Moskau der Hauptgrund für die Zurückhaltung Ankaras.

Vor allem im wirtschaftlichen Bereich ist die Türkei auf die Zusammenarbeit mit Russland angewiesen. Die Energieabhängigkeit von Moskau hat Ankara in den letzten Jahren mit Hilfe von Gaslieferungen von Aserbaidschan und Flüssiggas (LNG) reduziert. Es bleiben dennoch wichtige Faktoren im Türkei-Russland Verhältnis, die für Ankara von entscheidender Bedeutung sind. Russland leistet einen wesentlichen Beitrag für die türkische Wirtschaft, vor allem durch Tourismus und Handel. Im Jahr 2019 erreichte die Zahl der russischen Touristen in der Türkei mit sieben Millionen einen neuen Rekord, was einem Anteil von 16 Prozent aller Touristen in der Türkei entspricht. Zum Vergleich: Die Zahl der ukrainischen Touristen betrug rund 1,6 Millionen. Nicht unwichtig ist auch die Tätigkeit türkischer Baufirmen in Russland. Seit deren Eintritt 
in Russland Ende der 1980-er Jahre wurde das Gesamtvolumen der Bauprojekte türkischer Unternehmen in Russland im Jahr 2018 auf 71,8 Milliarden US-Dollar geschätzt. Russland ist damit der führende Auslandsmarkt für türkische Bauunternehmen. Der Gesamtwert der türkischen Bauprojekte in der Ukraine liegt bei vergleichsweise niedrigen 6,28 Milliarden US-Dollar.

Es waren nicht zuletzt die Auswirkungen auf die türkische Wirtschaft, die Ankara nach der Kampfjet-Krise im November 2015 wegen Syrien dazu bewegt haben, mit Moskau im Juni 2016 eine Versöhnung zu suchen. Seit der Bewältigung der Kampfjet-Krise haben Ankara und Moskau ihre Beziehungen erheblich erweitert. Der syrische Konflikt ist inzwischen der "Kleber« geworden, der Ankara und Moskau zusammenhält. Moskau und Ankara sind in Syrien aufeinander angewiesen, wenn es um ihre existenziellen Interessen geht: Regimesicherheit für Russland und kurdische Autonomiebestrebungen für die Türkei. Zudem kooperieren Russland und die Türkei im Bereich Atomenergie. Nicht zuletzt hofft Moskau auch bei den türkischen Weltraumambitionen behilflich zu sein.

Im Konflikt zwischen Russland und der Ukraine eine Seite wählen zu müssen fällt der Türkei daher sehr schwer. Laut einer vom türkischen Forschungsunternehmen Metropoll im April 2021 durchgeführten Meinungsumfrage wünschen sich 69,1 Prozent der Befragten, dass die Türkei in diesem Konflikt eine neutrale Haltung einnehmen soll, während 9,1 Prozent die russische und 3,8 Prozent die ukrainische Seite unterstützen. Auch der türkische Präsident Erdoğan hat sich nach dem Treffen am 10. April 2021 mit seinem ukrainischen Amtskollegen Selenskyj bemüht, zwischen Russland und der Ukraine zu manövrieren. So betonte Erdogan Ankaras Unterstützung für die Ukraine bei der KrimPlattform sowie für die Aussicht auf eine NATO-Mitgliedschaft für Kyjiw. Zugleich sendete Erdoğan eine Botschaft auch an den russischen Präsidenten Wladimir Putin, indem er sich für die Minsker Vereinbarungen als Grundlage für die Lösung im Donbas-Konflikt aussprach.

Im Konflikt zwischen Armenien und Aserbaidschan war die Strategie Ankaras darauf gerichtet, durch eine Veränderung des Status quo sich eine politische Rolle am Verhandlungstisch zu schaffen. Im Konflikt zwischen Russland und der Ukraine wäre die Veränderung des
Status quo nicht im Interesse der Türkei. Auch der Einsatz von Drohnen wäre hier nicht der entscheidende Faktor. Für Russland steht, anders als im Südkaukasus, im Donbas-Konflikt viel mehr auf dem Spiel. Ankaras Vorgehensweise im Konflikt zwischen Armenien und Aserbaidschan wurde in Moskau mit Zurückhaltung verfolgt und hat auch Gewinne für Russland - durch die Etablierung der Friedenstruppen in Bergkarabach - gebracht. Was die Ukraine anbelangt, warnte der russische Außenminister Sergei Lawrow die Türkei davor, den »militaristischen Stimmungen [der Ukraine] Vorschub zu leisten«.

\section{Außenpolitische Prioritäten der Türkei}

Das Hauptmerkmal der türkischen Außenpolitik besteht im ständigen Balancieren zwischen dem Westen und Russland. Dies funktioniert aber nur dann für die Türkei, wenn Ankara nicht gezwungen ist, zwischen zwei Stühlen einen wählen zu müssen. Vor dem Hintergrund der problematischen Beziehungen zwischen der Türkei und ihren NATO-Partnern im Nahen Osten und im östlichen Mittelmeerraum gilt gerade das Schwarze Meer als ein möglicher Ort, wo die Türkei ihre Position in der NATO stärken könnte.

Die Türkei war in der Vergangenheit in der Tat ein aktiver Mitgestalter in dieser Region. In der Zeit nach dem Kalten Krieg hat Ankara mehrere regionale Projekte in die Wege geleitet. 1992 wurde die SchwarzmeerWirtschaftskooperation gegründet. 2001 wurde die "Black Sea Naval Cooperation Task Group« (BLACKSEAFOR) für die Rettungsmaßnahmen und humanitäre Operationen von der Türkei initiiert. 2004 rief die Türkei des Weiteren die Marineoperation "Black Sea Harmony « ins Leben, die zur Sicherheit in der Region gegenüber Terrorismus und asymmetrischen Bedrohungen beitragen sollte. Bei allen diesen Maßnahmen war auch die Zusammenarbeit mit Russland nicht unwichtig.

Die türkische Führung wird ihre rhetorische Unterstützung der ukrainischen territorialen Integrität fortsetzen, während Ankara gleichzeitig darauf abzielt, die Lücken in seiner Verteidigungsindustrie mit ukrainischer Unterstützung zu füllen. Eine militärische Eskalation im Schwarzen Meer hingegen dürfte den Balanceakt der Türkei unmöglich machen.

\section{Über die Autorin}

Dr. Daria Isachenko arbeitet am Centrum für angewandte Türkeistudien (CATS) der Stiftung Wissenschaft und Politik in Berlin. Zu ihren Forschungsgebieten zählen die internationalen Beziehungen der Türkei sowie regionale und zwischenstaatliche Konflikte. 22.04.2021, https://www.wilsoncenter.org/blog-post/russia-escalates-where-do-turkey-ukraine-relations-stand. 
Handelsbeziehungen zwischen der Ukraine und der Türkei

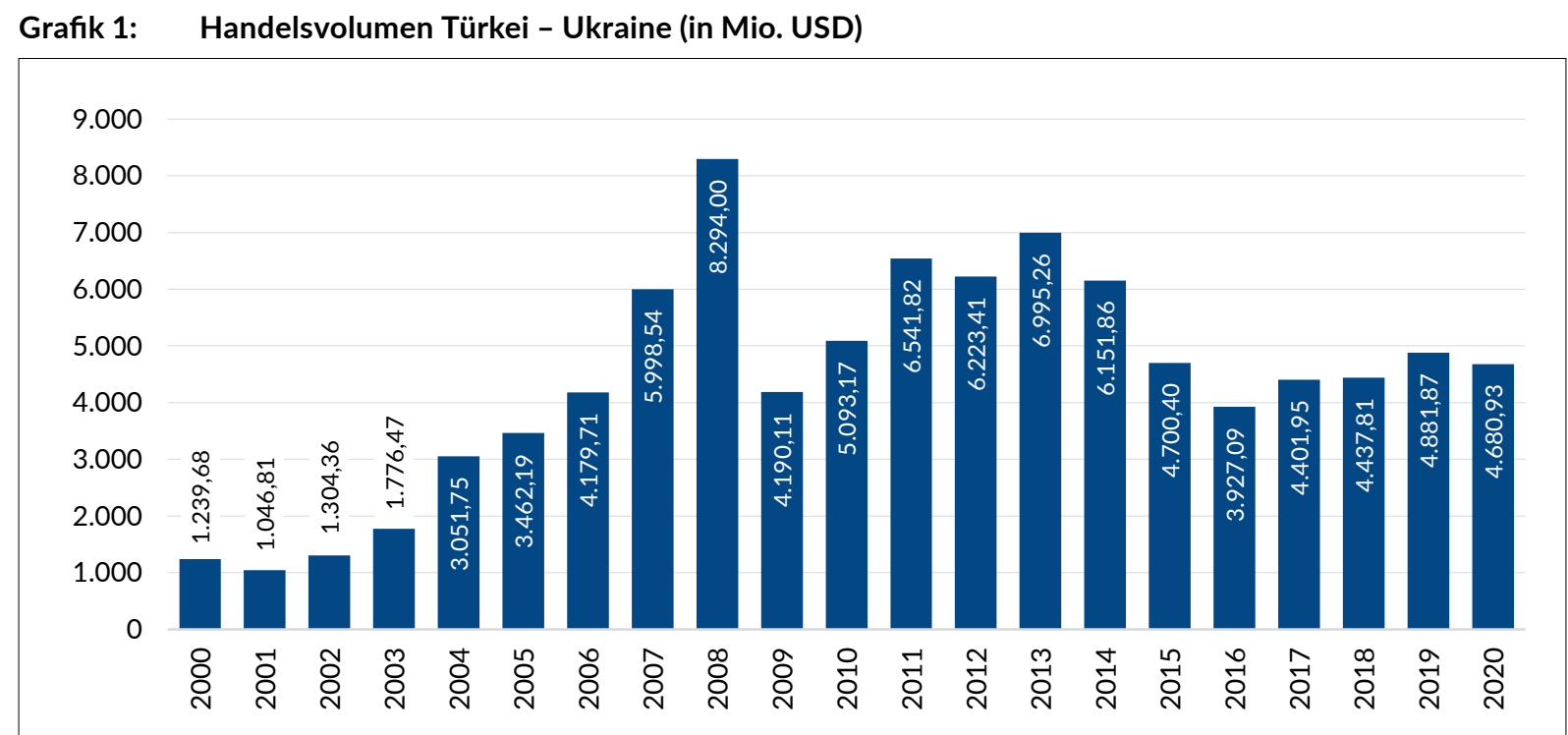

Quelle: IMF, »Türkei, Partnerland Ukraine«, https://data.imf.org/regular.aspx?key=61013712.

Grafik 2: Entwicklung der Exporte und Importe Ukraine - Türkei (in Mio. USD)

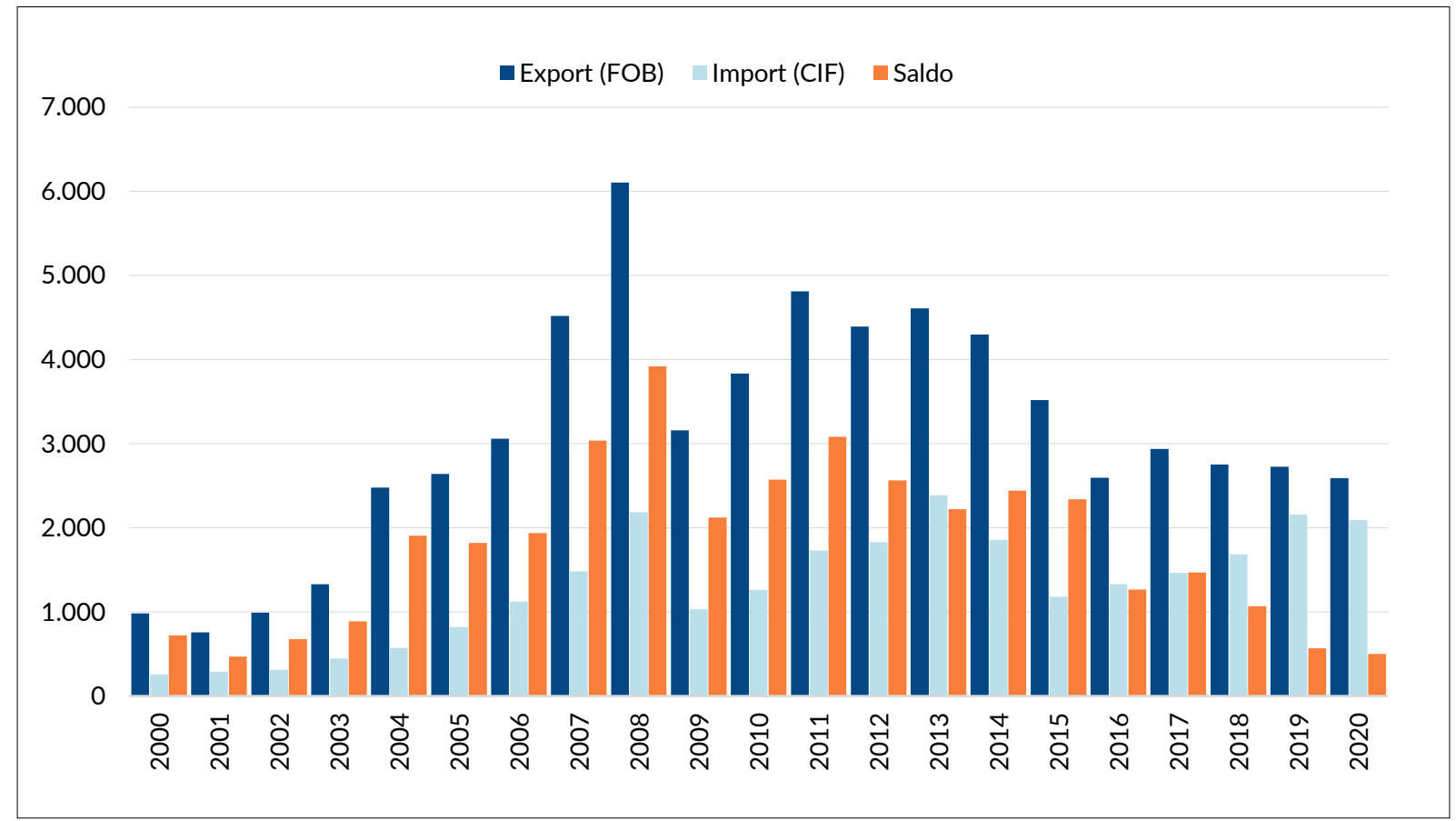

Quelle: IMF, »Türkei, Partnerland Ukraine», https://data.imf.org/regular.aspx?key=61013712. 
Grafik 3: $\quad$ Exporte aus der Ukraine in die Türkei (in Tsd. USD)

\begin{tabular}{|l|l|r|r|r|}
\hline 1 & Zwischenerzeugnisse & 1.438 .158 & $30,6 \%$ & \\
\hline 2 & Metalle & 1.168 .284 & $24,8 \%$ & \\
\hline 3 & Rohstoffe & 796.616 & $16,9 \%$ & \\
\hline 4 & Obst \& Gemüse & 600.346 & $12,8 \%$ & \\
\hline 5 & Lebensmittel & 163.944 & $3,5 \%$ & \\
\hline 6 & Holz & 112.106 & $2,4 \%$ & \\
\hline 7 & Mineralien & 103.286 & $2,2 \%$ & \\
\hline 8 & Konsumgüter & 73.216 & $1,6 \%$ & \\
\hline 9 & Chemikalien & 52.547 & $1,1 \%$ & \\
\hline 10 & Produktionsgüter & 43.770 & $0,9 \%$ & \\
\hline & Andere & 151.839 & $3,2 \%$ \\
\hline
\end{tabular}

Quelle: Weltbank - World Integrated Trade Solution, https://wits.worldbank.org/CountryProfile/en/Country/UKR/Year/2018/TradeFlow/EXPIMP/ Partner/TUR/Product/all-groups\#.

Grafik 4: Importe aus der Türkei in die Ukraine (in Tsd. USD)

\begin{tabular}{|l|l|r|r|}
\hline 1 & Konsumgüter & 506.722 & $14,9 \%$ \\
\hline 2 & Zwischenerzeugnisse & 406.535 & $12,0 \%$ \\
\hline 3 & Rohstoffe & 391.835 & $11,5 \%$ \\
\hline 4 & Produktionsgüter & 379.551 & $11,2 \%$ \\
\hline 5 & Obst \& Gemüse & 302.852 & $8,9 \%$ \\
\hline 6 & Textilien und Kleidung & 281.028 & $8,3 \%$ \\
\hline 7 & Maschinen und Elektrik & 268.129 & $7,9 \%$ \\
\hline 8 & Metalle & 184.431 & $5,4 \%$ \\
\hline 9 & Transportmittel & 158.313 & $4,7 \%$ \\
\hline 10 & Chemikalien & 137.812 & $4,1 \%$ \\
\hline & Andere & 381.737 & $11,2 \%$ \\
\hline
\end{tabular}

Quelle: Weltbank - World Integrated Trade Solution, https://wits.worldbank.org/CountryProfile/en/Country/UKR/Year/2018/TradeFlow/EXPIMP/ Partner/TUR/Product/all-groups\#. 


\section{Krieg und Frieden im Donbas: Lehren aus dem russischen Truppenaufmarsch}

Von Jakob Hauter (University College London)

DOI: $10.31205 /$ UA.251.03

\section{Zusammenfassung}

Der jüngste russische Truppenaufmarsch entlang der ukrainischen Grenze hat Ängste vor einer neuen Eskalation der Gewalt in der Ostukraine geweckt. An der Gesamtsituation in der Region haben jedoch weder der Aufmarsch dieser Truppen Anfang April noch ihr teilweiser Abzug Ende des Monats grundlegend etwas geändert. Die Gewalt entlang der Demarkationslinie brodelt weiter, wenn auch in geringem Maße. Das Risiko einer neuen russischen Offensive ist gering, darf aber keineswegs ausgeschlossen werden. Um die Wahrscheinlichkeit neuer Invasionsszenarien niedrig zu halten und gleichzeitig den festgefahrenen Friedensprozess wieder in Gang zu bringen, ist eine Erhöhung des wirtschaftlichen Drucks auf Russland zu überlegen.

\section{Die Lage entlang der Demarkationslinie}

Im Konfliktgebiet lässt sich seit Februar 2021 ein moderater Anstieg der Gewalt im Vergleich zum zweiten Halbjahr 2020 beobachten. Allerdings war es im Herbst 2020 entlang der Demarkationslinie im Donezbecken (Donbas) infolge eines im Juli vereinbarten Waffenstillstands auch so ruhig wie noch nie. Die Intensität der Kämpfe ist somit jüngst zwar gestiegen, bleibt aber verglichen mit der Situation vor dem Sommer 2020 relativ niedrig.

Der aussagekräftigste Indikator für die Intensität der Kämpfe in der Region ist die Zahl der Gefallenen auf ukrainischer Seite. Sie reflektiert das Ausmaß der Gewalt besser als zum Beispiel Angaben zur Zahl der Waffenstillstandsverletzungen, bei denen es schwer ist, den angerichteten Schaden zu quantifizieren. Todesfälle auf ukrainischer Seite werden zudem in der Regel gut dokumentiert - nicht nur von offizieller Seite, sondern auch von der vielfältigen ukrainischen Medienlandschaft sowie von den Kameraden und Familien der Gefallenen in sozialen Netzwerken. Diese Vielzahl an Informationsquellen, kombiniert mit der großen politischen, medialen und gesellschaftlichen Aufmerksamkeit für das Thema, macht es relativ schwierig, Todesfälle auf ukrainischer Seite der Front zu erfinden oder zu vertuschen. Auf Seite der zwei selbsterklärten »Volksrepubliken" gibt es hingegen keine verlässlichen Zahlen.

Die aktuell beste Quelle für einen Rückblick auf die letzten Jahre ist die von Mitarbeitern des militärhistorischen Museums der Ukraine ins Leben gerufene Online-Datenbank "Gedenkbuch der Gefallenen."Sie bietet umfassende und gut aufbereitete Zahlen für den Zeitraum 2014-2020. Laut dieser Zahlen tobten die heftigsten Kämpfe in der Region im Juli und August 2014. Nach dem ersten Minsker Abkommen Anfang September 2014 beruhigte sich die Situation etwas. Im Januar und Februar 2015 flammten die Kämpfe dann erneut auf. Seit dem zweiten Minsker Abkommen im Februar 2015 ist die Gewalt generell rückläufig. Sie kam jedoch nie ganz zum Erliegen. Daran änderte auch das jüngste Waffenstillstandsabkommen vom Juli 2020 nichts. Allerdings sank die Zahl der gefallenen ukrainischen Soldaten entlang der Demarkationslinie im zweiten Halbjahr 2020 mit 38 auf den niedrigsten Stand seit Beginn des Konflikts.

Für 2021 sind die Zahlen des "Gedenkbuchs der Gefallenen« noch nicht auf dem neuesten Stand. Jedoch publiziert die Webseite des ukrainischen Nachrichtensenders »24 Kanal» tagesaktuelle Daten. Sie sammelt Informationen zu gefallenen ukrainischen Soldaten in sozialen Netzwerken in Echtzeit, vor allem auf den Profilseiten verschiedener Einheiten des ukrainischen Militärs. Laut der Datenbank des Senders starben zwischen Anfang 2021 und Ende April insgesamt 37 ukrainische Soldaten an der Demarkationslinie. Verglichen mit den Daten des "Gedenkbuchs der Gefallenen" ist das die geringste Zahl für den Zeitraum Januar bis April jedes Jahres seit Beginn des Krieges. Im Vergleich zum Herbst 2020 ist die Zahl aber klar gestiegen und ist bereits fast genauso hoch wie im gesamten zweiten Halbjahr 2020.

\section{Invasionsszenarien}

Für sich genommen deutete der moderate Anstieg der Gewalt entlang der Demarkationslinie seit Februar 2021 also kaum auf eine dramatische Eskalation des Konfliktes hin. Im Kontext massiver russischer Truppenbewegungen im Umfeld der Konfliktregion bot er jedoch Anlass zu ernsthafter Sorge, die von der ukrainischen Regierung und Zivilgesellschaft auch mit Nachdruck geäußert wurde. Russland begann Ende März 2021 massiv Truppen und Kriegsgerät in Richtung ukrainische Grenze und auf die annektierte Halbinsel Krim zu verlegen. Der Kreml selbst machte keine 
Angaben zur Anzahl der verlegten Truppen. Der Europäische Auswärtige Dienst sprach am 20. April von mehr als 100.000 Soldaten. Eine Woche vorher sprachen die ukrainischen Behörden von 40.000 Soldaten nahe der Stadt Woronesch (ca. 450 Kilometer nördlich der Konfliktregion) und von weiteren 40.000 Soldaten auf der Krim. Es blieb unklar, auf welchen Quellen und Methoden diese Schätzungen beruhten. Dass ein massiver Truppenaufmarsch stattgefunden hatte, stand jedoch außer Frage und wurde durch zahlreiche öffentlich zugängliche Quellen belegt. Zum Beispiel verifizierten die Analysten des russischen Recherchekollektivs "Conflict Intelligence Team « zahlreiche Internetvideos langer Militärkonvois und konnten diese eindeutig Orten nahe der ukrainischen Grenze zuordnen. Außerdem zeigten öffentlich zugängliche Satellitenbilder große neu entstandene Militärlager nahe der Stadt Woronesch und auf der annektierten Krim.

Der parallele Truppenaufmarsch in Woronesch und auf der Krim weckte Ängste vor einer großen russischen Offensive. Einige Beobachter befürchteten, die russischen Streitkräfte könnten gleichzeitig das ukrainische Festland nördlich der Krim sowie den Norden der Provinz Luhansk angreifen. Theoretisch könnte Russland dann in einer Zangenbewegung einen Landkorridor zwischen der Krim und den zwei „Volksrepubliken« im Donbas schaffen und deren Gebiet zugleich auf die gesamten Provinzen Donezk und Luhansk erweitern. Der Kreml könnte versuchen, eine solche Offensive damit zu rechtfertigen, die russischen Staatsbürger auf der Krim und im Donbas vor angeblich bevorstehenden ukrainischen Angriffen schützen zu müssen. Auf der annektierten Krim haben so gut wie alle Bewohner die russische Staatsbürgerschaft erhalten, und auch in den beiden "Volksrepubliken" erhielten nach übereinstimmenden Angaben beider Seiten bereits mehr als 500.000 Bewohner russische Pässe. In sozialen Netzwerken kursierten sogar noch weiterreichende Szenarien, bis hin zu einer kompletten Besetzung der Ukraine östlich des Dnipro, was Kyjiw zum Kriegsschauplatz machen würde.

Von einer neuen Offensive gegen die Ukraine könnte Russland potenziell in zweierlei Hinsicht profitieren. Zum einen würde die Kontrolle über den Nord-KrimKanal, durch den Wasser vom Dnipro auf die Krim geleitet werden kann, Russland dabei helfen, die Wasserknappheit auf der Halbinsel zu bekämpfen. Bis 2014 erfolgte bis zu 85 Prozent der Wasserversorgung der Krim über diesen Kanal. Nach der russischen Annexion verringerte die ukrainische Regierung die Wasserzufuhr durch den Kanal zunächst drastisch und stoppte sie schließlich ganz. Seitdem trocknet die Halbinsel zunehmend aus; in großen Städten gibt es oft nur für wenige Stunden am Tag fließendes Wasser. Da Russland bisher nicht im großen Maßstab in Meerwasserentsal- zung investiert hat, ist anzunehmen, dass sich das Problem in den kommenden Jahren weiter verschärfen wird.

Zum anderen könnte Russland versuchen, eine militärische Offensive zur innenpolitischen Konsolidierung zu nutzen. Angesichts zahlreicher innenpolitischer und wirtschaftlicher Probleme und im Hinblick auf die anstehenden Parlamentswahlen im September könnte sich der Kreml von einer neuen Offensive einen ähnlichen Popularitätsschub erhoffen, wie er nach der Krim-Annexion zu beobachten war.

Jedoch wäre eine militärische Eskalation der Lage für Russland auch mit beträchtlichen Risiken verbunden. Zwar bleiben die ukrainischen Streitkräfte den russischen in Bezug aufTruppenstärke und Ausrüstung weit unterlegen, sie sind aber mittlerweile deutlich besser in der Lage, auf eine russische Offensive zu reagieren als noch 2014. Sie könnten also die materiellen und personellen Kosten eines russischen Angriffs deutlich in die Höhe treiben. Hinzu kämen noch die Kosten für die dauerhafte Besatzung eroberter Gebiete. Es ist außerdem zu bezweifeln, dass ein sich in die Länge ziehender Krieg mit zahlreichen gefallenen russischen Soldaten eine ähnlich konsolidierende Wirkung auf die russische Gesellschaft hätte, wie die schnelle und unblutige Annexion der Krim im Jahr 2014. Trotz der Zurückhaltung des Westens in der Vergangenheit wären härtere internationale Sanktionen gegen Russland im Falle einer neuen Offensive in einem solchen Szenario ebenfalls kaum zu vermeiden.

Diese Risiken für den Kreml wachsen mit dem Ausmaß einer hypothetischen Offensive. Das am wenigsten unwahrscheinliche Szenario ist daher ein schneller Überraschungsangriff von der Krim aus auf die Oblast Cherson und die Besetzung des südlichen Teils dieser Oblast östlich des Dnipro. So könnte sich Russland die Kontrolle über den Nord-Krim-Kanal sowie über einen weiteren Teil der ukrainischen Schwarzmeerküste sichern und gleichzeitig versuchen, seine Offensive als humanitäre Aktion zum Schutz der von Wasserknappheit bedrohten Krim-Bevölkerung zu präsentieren. Natürlich würde selbst eine begrenzte Offensive dieser Art bereits beträchtliche Kosten mit sich bringen. Allerdings kennt niemand außer den unmittelbar Beteiligten im Kreml die genaue Kosten-Nutzen-Einschätzung sowie den intransparenten Entscheidungsprozess der russischen Staatsführung. Es ist deshalb in jedem Fall ratsam, dass die Ukraine und ihre internationalen Partner auf dieses und andere Krisenszenarien vorbereitet sind. Zum gegenwärtigen Zeitpunkt mögen solche Szenarien nach dem am 22. April angekündigten teilweisen russischen Truppenabzug wieder etwas an Wahrscheinlichkeit verloren haben. Am Umfang dieses Abzugs gibt es jedoch Zweifel. Laut dem russischen Abzugsbefehl wird das nach Woronesch verlegte schwere Kriegsgerät dort stationiert bleiben - angeblich 
zur Vorbereitung auf das für den Spätsommer geplante Großmanöver »Sapad 2021.«Außerdem bleibt unklar, wie viele Truppen tatsächlich die Grenzregion verlassen. Anfang Mai schätzte die US-Regierung die Zahl der entlang der ukrainischen Grenze stationierten russischen Truppen immer noch auf fast 80.000 Soldaten. Der ukrainische Präsident Wolodymyr Selenskyj behauptete nach einem Treffen mit US-Außenminister Blinken am 6. Mai, dass Russland bisher lediglich 3.500 Soldaten von der Krim abgezogen habe.

\section{Die Handlungsoptionen des Westens}

Im Zuge des jüngsten russischen Truppenaufmarschs haben sich Präsident Selenskyj und sein Außenminister Dmytro Kuleba sehr aktiv um internationale Unterstützung bemüht. Im Hinblick auf diplomatische Statements waren diese Bemühungen auch erfolgreich. In EU und NATO bekräftigte man einhellig die Solidarität mit der Ukraine und forderte Russland zur Deeskalation und zum Truppenrückzug auf. Es bleibt jedoch offen, inwieweit der Westen tatsächlich bereit ist, diesen Worten auch Taten folgen zu lassen.

Was militärische Abschreckungsmaßnahmen angeht, zeigte sich der Westen zurückhaltend. Medienberichten zufolge sah die US-Regierung von der ursprünglich geplanten Entsendung zweier Zerstörer ins Schwarze Meer ab, um die Situation nicht weiter zu eskalieren. Auf die erneut mit Nachdruck geäußerten NATO-Mitgliedschaftsambitionen der ukrainischen Regierung reagierte man im Bündnis höflich, aber reserviert (siehe dazu die Analyse von Susan Stewart in dieser Ausgabe). Auch wenn diese Zurückhaltung von einigen Experten kritisch gesehen wird, ist sie aus strategischer Sicht nachvollziehbar. Militärische Abschreckungsmaßnahmen sind nur dann potenziell wirksam, wenn sie glaubhaft sind. Zerstörer im Schwarzen Meer können den Kreml nur dann beeinflussen, wenn die Entscheidungsträger dort befürchten, dass diese Zerstörer im Ernstfall ukrainische Schiffe durch eine russische Seeblockade eskortieren oder die ukrainische Küste bei einer russischen Invasion verteidigen würden. Genauso sind Schritte in Richtung einer ukrainischen NATO-Mitgliedschaft nur dann ein potenzielles Druckmittel, wenn Moskau tatsächlich glaubt, die NATO sei bereit, die Ukraine trotz ihrer territorialen Konflikte mit Russland aufzunehmen und auch im Falle eines Angriffs zu verteidigen. Beides ist in der aktuellen Situation mit hoher Wahrscheinlichkeit nicht der Fall. Zwar ist die angebliche Einkesselung und direkte Bedrohung Russlands durch die NATO ein Dauerthema in den russischen Staatsmedien, aber es darf bezweifelt werden, dass die Entscheidungsträger im Kreml in dieser Hinsicht tatsächlich ihrer eigenen Propaganda glauben. Wahrscheinlicher ist, dass man in Moskau versteht, dass die NATO nicht bereit ist, zur
Verteidigung der Ukraine direkte militärische Zusammenstöße mit Russland zu riskieren. Der Versuch militärischer Abschreckung von Seiten des Westens wäre in der aktuellen Situation also ein Bluff, den Russland mit hoher Wahrscheinlichkeit durchschauen würde.

Vor diesem Hintergrund wäre die ukrainische Außenpolitik besser beraten, ihre diplomatischen Bemühungen auf die Ausrüstung des eigenen Militärs auf der einen Seite und die Drohung des Westens mit Wirtschaftssanktionen gegenüber Russland auf der anderen zu konzentrieren. Diese beiden Dimensionen sind der realistischere Weg, die Kosten und Risiken einer erneuten russischen Offensive zu erhöhen. Auch hier sind die Erfolgsaussichten jedoch ungewiss. Vor allem in der EU bleibt die Skepsis gegenüber Waffenlieferungen an die Ukraine groß. Die USA sind in dieser Hinsicht aber aufgeschlossener und haben bereits über 300 Panzerabwehrraketen vom Typ Javelin an die Ukraine geliefert. Ein Gesetz, das jährliche Militärhilfen für die Ukraine von bis zu 300 Millionen US-Dollar im Zeitraum 2022-2026 vorsieht, wurde im März von Vertretern beider Parteien in den US-Senat eingebracht. Allerdings befindet es sich noch in einer frühen Phase des Gesetzgebungsprozesses. Öffentliche westliche Sanktionsdrohungen für den Fall einer russischen Offensive hielten sich ebenfalls in Grenzen. Die am 15. April verkündeten neuen US-Sanktionen sendeten zwar ein gewisses Signal, allerdings wurden diese Sanktionen primär als Reaktion auf die russische Einmischung in US-Wahlen und russische Hackerangriffe auf US-Institutionen präsentiert. Ein weiteres Signal war eine Resolution des Europaparlaments, die am 29. April verabschiedet wurde. Im Falle einer russischen Offensive gegen die Ukraine fordert diese Resolution eine Einstellung der Erdöl- und Erdgaseinfuhren aus Russland, die Abkopplung Russlands vom Zahlungssystem SWIFT und das Blockieren von Vermögenswerten und Visa russischer Oligarchen und ihrer Familien. Jedoch ist diese Resolution nicht bindend und die Rhetorik im Europaparlament ist traditionell schärfer als in den Regierungen der EU-Mitgliedsstaaten. In Deutschland laufen große wirtschaftliche Kooperationsprojekte - allen voran die Gaspipeline Nord Stream II - derweil relativ ungestört weiter, und Bundesaußenminister Heiko Maas lehnte in einem Fernsehinterview am 25. April weitere Sanktionen gegenüber Russland $a b$.

Dennoch ist der Handlungsspielraum des Westens und vor allem der EU im wirtschaftlichen Bereich am größten. Drohungen mit Einreisesperren für Russlands Politik- und Wirtschaftselite, mit dem Einfrieren von Vermögenswerten, mit der Abkopplung Russlands vom SWIFT-Zahlungssystem und mit einer allgemeinen Reduktion wirtschaftlicher Kooperationen, inklusive Rohstoffimporte, hätten am ehesten das Potenzial, die Wahrscheinlichkeit einer neuen russischen Offensive 
gegen die Ukraine gering zu halten. Diese Drohungen müssten nicht zwingend öffentlich erfolgen. Aber es ist wichtig, dass sie in einer Weise kommuniziert werden, die der Kreml versteht und ernst nimmt.

\section{Fazit: Gibt es Aussichten auf einen befriedeten Donbas?}

Natürlich kann die Verhinderung einer neuen Eskalation des Konflikts immer nur das absolute Minimalziel sein. Denn auch ohne eine neue russische Offensive bleibt die Lage entlang der Demarkationslinie angespannt. Gleichzeitig sind die innenpolitischen Hürden für eine Reintegration der "Volksrepubliken" in die Ukraine weniger hoch als die außenpolitische Hürde, die Russland durch seine militärische und politische Kontrolle über diese Gebiete geschaffen hat. Die andauernd hohe Unterstützung für die als pro-russisch geltende "Oppositionsplattform - für das Leben« im ukrainisch kontrollierten Teil des Donbas bei Präsidentschafts-, Parlaments- und Kommunalwahlen zeugt davon, dass sich die politischen Einstellungen auf ukrainischer Seite der Demarkationslinie nicht grundlegend verändert haben. Von einer ukrainisch-nationalistischen Indoktrinierung und Radikalisierung der lokalen Bevölkerung und von weitverbreitetem Hass gegenüber den Bewohnern der "Volksrepubliken« kann keine Rede sein. Vielmehr zeugt die Popularität der Oppositionsplattform von einer weitverbreiteten Sehnsucht nach Frieden und Stabilität sowie von Nostalgie für die Vorkriegszeit. Separatistische Ideen scheinen aber ebenfalls wenig populär zu sein. Laut einer Umfrage des Kyjiwer Instituts für Soziologie im Auftrag des Berliner Zentrums für Osteuropa- und internationale Studien (ZOiS), lag die Unterstützung einer Unabhängigkeit des Donbas oder eines Beitritts zu Russland im ukrainisch kontrollierten Teil des Gebiets zusammengenommen bei unter 10 Prozent.

Auf Seiten der "Volksrepubliken" hingegen zeigte eine Umfrage des Moskauer Lewada-Zentrums, ebenfalls im Auftrag des ZOiS, dass mehr als die Hälfte der Bewohner einen Beitritt zu Russland befürworten und sich nur knapp mehr als 10 Prozent für eine Reintegration in die Ukraine aussprachen. Da die politische Führung der "Volksrepubliken" jedoch ausgesprochen repressiv gegen jeglichen Dissens vorgeht, sollte den Ergebnissen dieser Meinungsumfrage eine gewisse Skepsis entgegengebracht werden. Angesichts der schlechten wirtschaftlichen und sozialen Lage in den "Volksrepubliken« kann man auch dort von einer gewissen Kriegsmüdigkeit und Desillusionierung gegenüber Russland ausgehen. Auch wurden die sozialen Kontakte über die Demarkationslinie hinweg nie völlig gekappt. Zahlreiche Bewohner der "Volksrepubliken« reisten regelmäßig auf die ukrainische Seite, um dort zum Beispiel ihre ukrainische Rente entgegenzunehmen oder ihre Familien zu besuchen. Durch
Maßnahmen im Zuge der Coronavirus-Pandemie wurden solche Reisen erheblich erschwert, da die "Volksrepubliken « die meisten ihrer Kontrollpunkte geschlossen haben. Es kann jedoch davon ausgegangen werden, dass sie wieder an Popularität gewinnen, wenn geschlossene Kontrollpunkte wieder öffnen und der Übergang über die Demarkationslinie erleichtert wird. Von einer völligen Abkopplung der "Volksrepubliken" vom Rest der Region kann also keine Rede sein. Es besteht vielmehr Grund zur Hoffnung, dass ein groß angelegtes international finanziertes Wiederaufbauprogramm lokale Aversionen gegen eine Wiedereingliederung der "Volksrepubliken" in die Ukraine effektiv abbauen könnte. Ein solches Wiederaufbauprogramm müsste allerdings erst noch entwickelt und finanziert werden und würde vermutlich vor allem aufseiten des Westens eine beträchtliche Zahlungsbereitschaft voraussetzen.

Die entscheidende Grundvoraussetzung für eine solche Wiedereingliederung wäre jedoch die Bereitschaft Russlands, vor allem seine militärische und politische Kontrolle über die »Volksrepubliken« aufzugeben. Dies wiederum wird ohne internationalen Druck kaum zu erreichen sein. Hauptziel der Friedensbemühungen Deutschlands, der EU und der USA im Donbas muss also sein, die Kosten-Nutzen-Analyse Moskaus in Richtung einer Aufgabe der "Volksrepubliken« zu bewegen. Hier legt die Erfahrung der letzten Jahre leider nahe, dass die Aussicht auf Aufhebung der bisher verhängten Sanktionen nicht ausreichend ist. Es muss daher vermehrt darüber nachgedacht werden, ob es nicht auch in Abwesenheit einer neuen Eskalation erforderlich sein könnte, den Druck auf Russland weiter zu erhöhen, um so wieder Bewegung in den festgefahrenen Friedensprozess zu bringen. Von deutscher Seite würde zum Beispiel ein Moratorium für die Nord Stream II Pipeline in diesem Zusammenhang ein klares Zeichen setzen.

Natürlich muss eine Erhöhung des internationalen Drucks auf Russland mit Augenmaß erfolgen. Es muss eine Situation geschaffen werden, in der Moskau versteht, dass es von einer Aufgabe des Donbas profitieren würde, während eine weitere Eskalation der Situation mit dramatischen zusätzlichen Kosten verbunden wäre. Dieser schwierige diplomatische Balanceakt ist aktuell die zentrale Herausforderung der Russlandpolitik von Deutschland, EU und USA. Der jüngste russische Truppenaufmarsch hat diese Herausforderung wieder ins Scheinwerferlicht der Öffentlichkeit gerückt. Es bleibt zu hoffen, dass er auch die Aufmerksamkeit politischer Entscheidungsträger wieder verstärkt und nachhaltig auf die Situation in der Ostukraine gelenkt hat. Wenn dem so ist, wäre den Ereignissen des letzten Monats zumindest etwas Positives abzugewinnen. Informationen über den Autor und Lesetipps finden Sie auf der nächsten Seite. 


\section{Über den Autor}

Jakob Hauter ist seit Herbst 2018 Doktorand an der School of Slavonic and East European Studies des University College London. Sein Promotionsprojekt beschäftigt sich mit dem Verhältnis interner und externer Faktoren während der Eskalation des Krieges in der Ostukraine und mit dem Potenzial von Internetmedien als Quellen für die wissenschaftliche Analyse dieses Eskalationsprozesses. Er ist Herausgeber eines Sammelbandes sowie Autor zweier wissenschaftlicher Artikel zum Krieg im Donbas:

- Hauter, Jakob (ed.). 2021. Civil War? Interstate War? Hybrid War? Dimensions and Interpretations of the Donbas Conflict in 2014-2020. Stuttgart: ibidem-Verlag. https://bit.ly/donbas-sammelband

- Hauter, Jakob. 2021. "How the War Began: Conceptualizing Conflict Escalation in Ukraine’s Donbas." The Soviet and Post-Soviet Review. Advance online publication. Open access. https://doi.org/10.30965/18763324-20201380

- Hauter, Jakob. 2019. "Delegated Interstate War: Introducing an Addition to Armed Conflict Typologies." Journal of Strategic Security 12 (4): 90-103. Open access. https://doi.org/10.5038/1944-0472.12.4.1756

Lesetipps/Bibliografie

- 24 Kanal, 2021. „Wina na Donbasi: Skilky wiskovych wsche sahynuly u 2021 rozi.» https://novyny.24tv.ua/ skilki-zaginulo-na-donbasi-2021-kilkist-zhertv_n1498581

- Conflict Intelligence Team. Twitter Account. https://twitter.com/CITeam_en

- Gedenkbuch der Gefallenen [Knyha pamjati polehlych sa Ukrajinu]. http://memorybook.org.ua/

- Hauter, Jakob. »Eskalation des Konfliktes im Donbas - vor sieben Jahren und heute.« Ukraine verstehen. 13. April 2021. https://ukraineverstehen.de/hauter-eskalation-des-konfliktes-im-donbas/

- O'Loughlin, John, Gwendolyn Sasse, Gerard Toal und Kristin M. Bakke. "A new survey of the Ukraine-Russia conflict finds deeply divided views in the contested Donbas region." The Washington Post. 12. Februar 2021. https://www.washingtonpost.com/politics/2021/02/12/ new-survey-ukraine-russia-conflict-finds-deeply-divided-views-contested-donbas-region/

- Reuters. „Russian military build-up near Ukraine numbers more than 100,000 troops, EU says.« 20. April 2021. https://www.reuters.com/world/europe/russian-military-build-up-near-ukraine-numbers-more-than-150000troops-eus-2021-04-19/

\section{STATISTIK}

\section{Konflikt im Donbas}

\section{Grafik 1: Von der OSZE SMM registrierte Waffenstillstandsverletzungen}

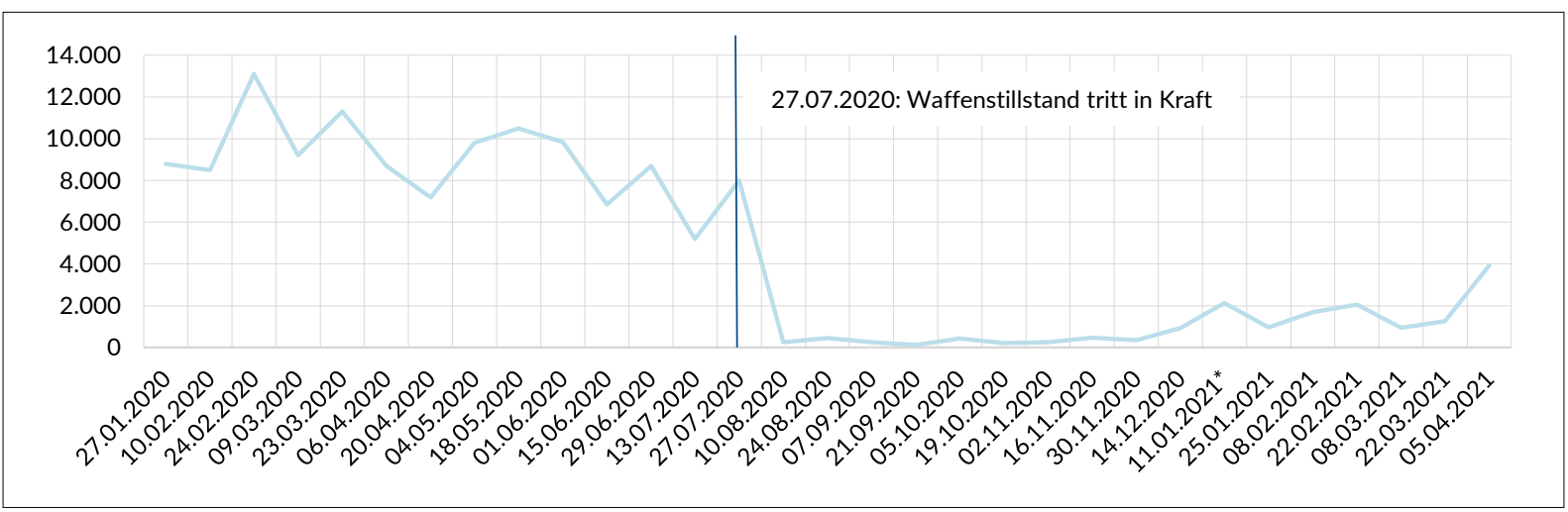

*Berichtszeitraum aufgrund der Weihnachtsferien länger, 14.12.2020 - 10.01.2021.

Quelle: Status Reports of the Special Monitoring Mission to Ukraine, https://www.osce.org/special-monitoring-mission-to-ukraine/157261. 


\section{Grafik 2: $\quad$ Einschränkung der Bewegungsfreiheit der OSZE SMM}

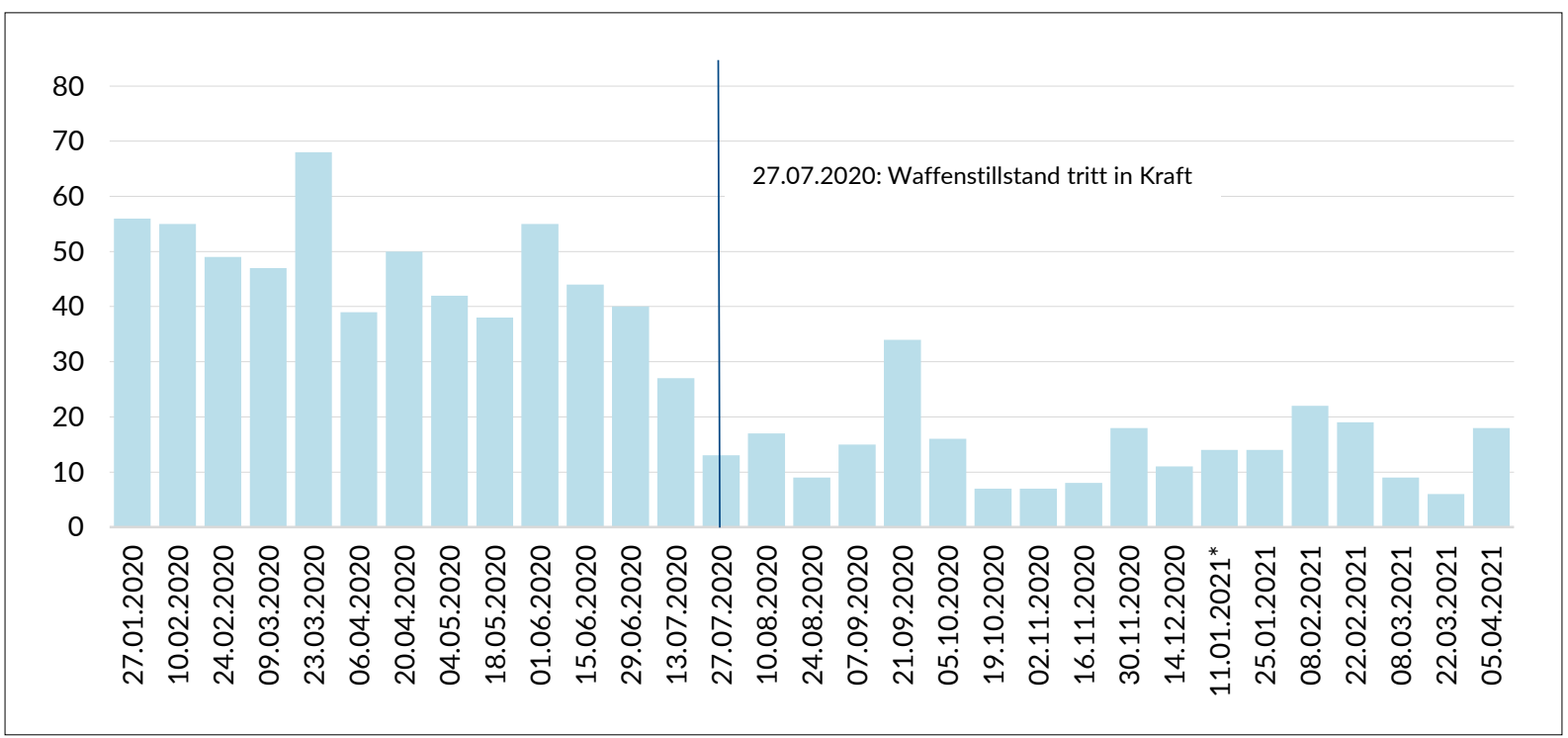

${ }^{*}$ Berichtszeitraum aufgrund der Weihnachtsferien länger, 14.12.2020 - 10.01.2021.

Quelle: Status Reports of the Special Monitoring Mission to Ukraine, https://www.osce.org/special-monitoring-mission-to-ukraine/157261.

\section{Grafik 3: Auf welchem Territorium die Bewegungsfreiheit der OSZE SMM eingeschränkt wurde}

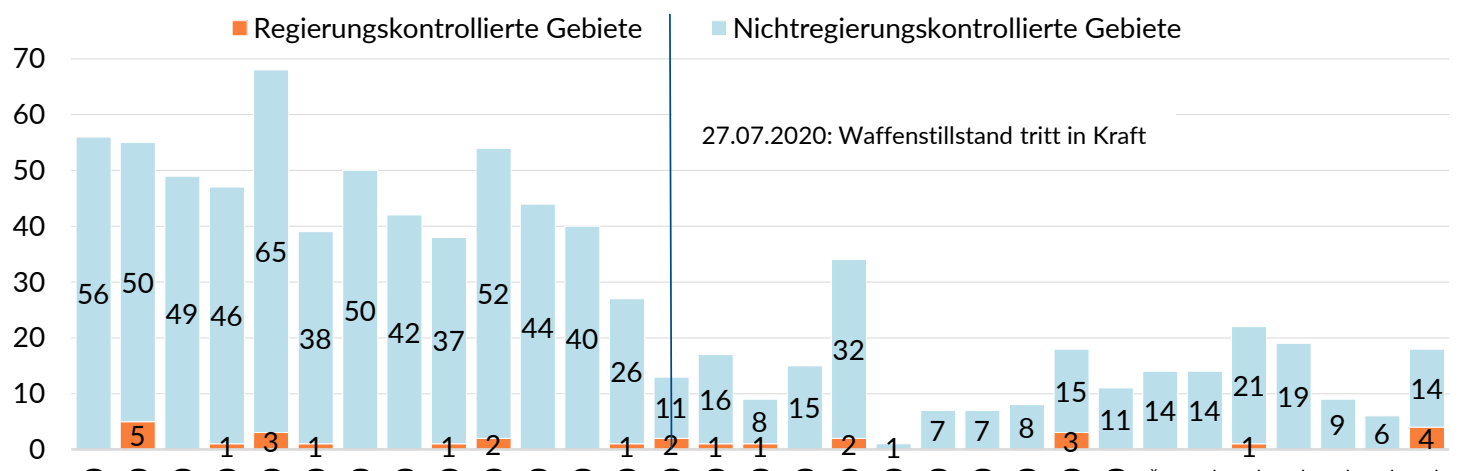

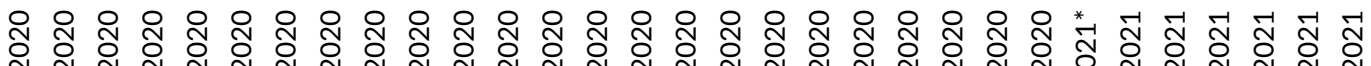

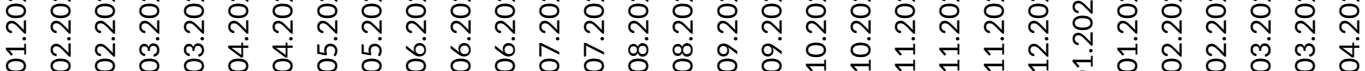

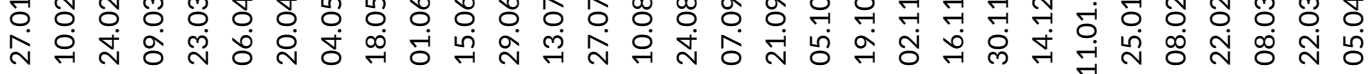

*Berichtszeitraum aufgrund der Weihnachtsferien länger, 14.12.2020 - 10.01.2021.

Quelle: Status Reports of the Special Monitoring Mission to Ukraine, https://www.osce.org/special-monitoring-mission-to-ukraine/157261. 
Grafik 4: Gefallene ukrainische Soldaten im Donbas, April 2014 - April 2021

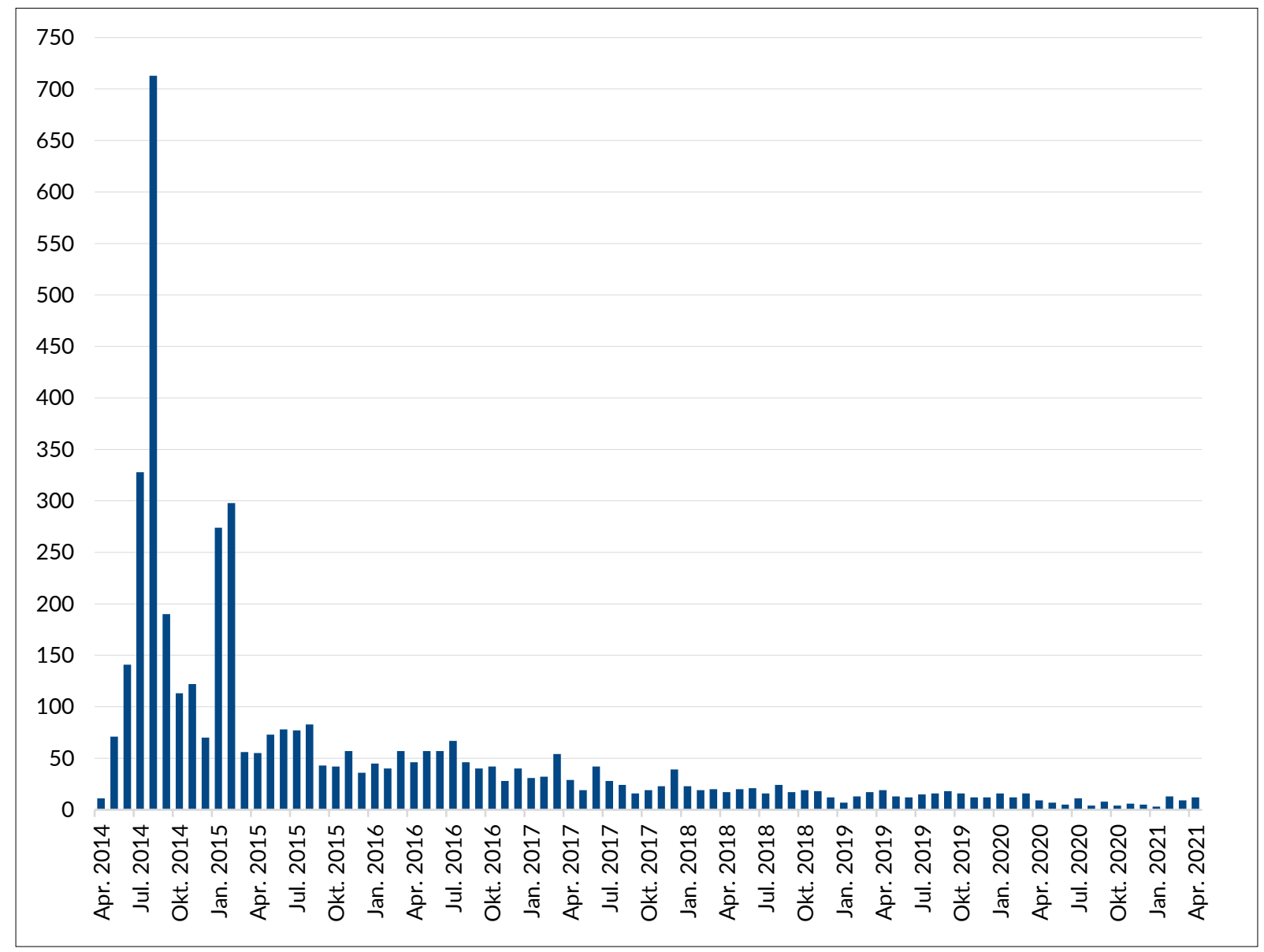

Quelle: http://memorybook.org.ua.

Grafik 5: Wie hoch schätzen Sie die Wahrscheinlichkeit einer militärischen Invasion der Ukraine durch Russland ein?

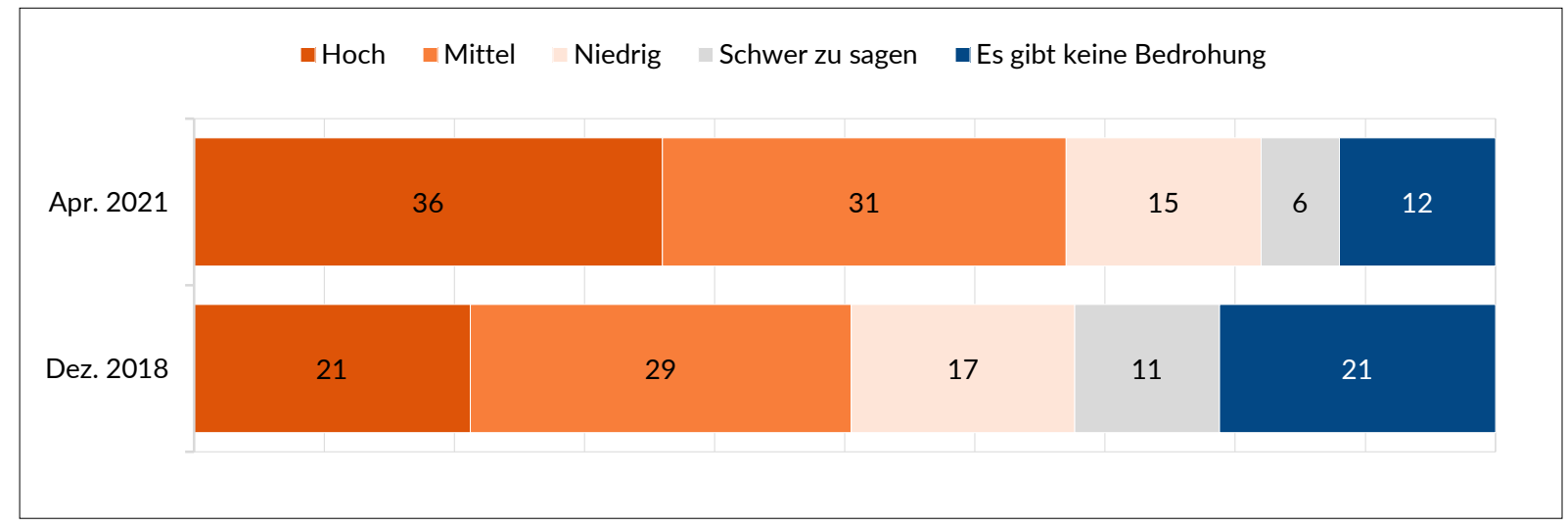

Quelle: Repräsentative Rating-Umfrage, 09.04.2021, http://ratinggroup.ua/ru/research/ukraine/obschestvenno-politicheskie_nastroeniya_ naseleniya_6-7_aprelya_2021.html. 


\section{Vom Säbelrasseln zum Krieg?}

Von Fjodor Krascheninnikow

\section{Einleitung der Dekoder-Redaktion}

Im Osten der Ukraine bahnt sich eine neue Krise an: Seit dem Frühjahr gibt es vermehrt Schusswechsel, trotz einer vereinbarten Waffenruhe sind 2021 schon rund 50 Menschen gestorben. Während der Kreml Truppenverlegungen an die ukrainische Grenze anordnet, läuft die Propaganda des russischen Staatsfernsehens auf Hochtouren: Die Ukraine bereite einen Angriff vor, Russlands "Friedenstruppen« seien bereit, im Donbass einzumarschieren und dort für Ordnung zu sorgen, so der Tenor.

Die Ukraine versetzt Truppen in Bereitschaft und sucht Beistand im Ausland: In einem Telefonat mit dem ukrainischen Präsidenten Selensky sagte Joe Biden, dass die Ukraine auf die »unerschütterliche Unterstützung« Amerikas zählen könne.

Die Einschätzungen der Lage gehen in Russland weit auseinander: Der russische Militärexperte Pawel Felgengauer glaubt etwa, dass die Krise sich im Extremfall sogar zu einem Weltkrieg auswachsen könne. Für Felgengauers Mitstreiter Alexander Golz ist sie vor allem Säbelrasseln, das dem Aufbau einer Drohkulisse gegenüber dem Westen dient.

Auch Fjodor Krascheninnikow argumentiert, dass Putin wohl keinen neuen Krieg will. Auf Republic kommentiert der Journalist, was der Kreml mit der aktuellen Eskalation beabsichtigt und warum die Situation trotz allem brandgefährlich ist.

$\mathrm{W}$ arum braucht Putin einen Krieg? Die Frage mag denen idiotisch erscheinen, die schon alle Argumente rauf und runtergenudelt haben: Die Beliebtheitswerte sinken, der Westen will nur über Nawalny reden, und überhaupt - die weltumspannende Figur des Dr. Evil verlangt nach Aggression. Beständiges Geheul im Sumpf der Propaganda. Irgendwas hat das doch zu bedeuten. Gerade mit dem ganzen Militärgerät vor Augen.

Die Staffeln von Militärgerät wirken besonders beunruhigend. Das geflügelte Wort, dass auch eine ungeladene Pistole einmal im Jahr losgeht, lässt Bedenken aufkommen, ob Riesenmengen an schweren Waffen und Soldaten, die sich am selben Ort befinden, nicht unweigerlich mit einer Schießerei enden.

Alles andere ist bei genauerem Nachdenken bedeutungslos. Bereitet man sich auf einen echten Krieg vor, dann jault man darüber nicht von morgens bis abends.

Das Ergebnis ist irgendein Blödsinn: Putin hat beschlossen Krieg zu führen, hat dem Gegner aber einen Haufen Zeit gegeben sich vorzubereiten. Und damit der mehr Argumente zur Mobilisierung der Nachbarn zwecks Unterstützung hat - wird noch Angst geschürt und von morgens bis abends demonstriert, wie ernsthaft das Vorhaben ist. Es gibt natürlich alles Mögliche, aber das ist die dümmste aller Kriegsvorbereitungen, die man sich vorstellen kann.

Wie sehr sich Chauvinisten auch versichern, dass die Ukraine keine Armee hat, keine hatte und keine haben wird - das entspricht im Frühjahr 2021 nicht den Tatsachen: Es gibt dort eine Armee, und selbst wenn es nicht die beste auf der Welt ist, so kann sie dem Gegner doch Schaden zufügen. Schaden - das bedeutet, falls es jemand nicht verstanden hat, Leichen unter unseren Landsleuten. Hunderte, tausende, im schlimmsten Fall zehntausende Leichen.

\section{1 ist nicht 2014}

Der Unterschied zwischen unserer Zeit und der jüngsten Vergangenheit besteht darin, dass Opfer in der Gesellschaft schon lange nicht mehr als etwas Selbstverständliches angesehen werden. Es ist kein Zufall, dass die im letzten Ukrainekrieg und bei anderen geopolitischen Abenteuern Gefallenen ohne großen Pathos beerdigt werden und großer Aufwand betrieben wird, damit ihre Familien nicht vor aller Augen trauern. Das Krim-Epos brachte Putin einen so großen Erfolg ein, weil beim Normalbürger der Eindruck entstand, es wäre kein Blut geflossen.

Ich wage zu behaupten, dass selbst der schwächste Widerstand der ukrainischen Armee unsere Falken verschrecken und überhaupt die ganze patriotische Messe vermiesen könnte: Höfliche Menschen, die von Krimbewohnern mit Blumen begrüßt werden, und ein ukrainischer Admiral, der in den russischen Dienst überläuft - das ist eine Sache. Aber Krieg, Leichen und Schusswechsel sind eine völlig andere Sache. Kommt mir nicht mit "Rückkehr in den Heimathafen«. Es ist völlig offensichtlich, dass die ukrainische Armee im Jahr 2021 bereit ist für einen Krieg. Schüsse und Opfer wird man da auf keinen Fall vermeiden können.

Der Krieg als Möglichkeit, um den Verhandlungen mit dem Westen einen anderen Dreh zu geben, scheint eine logische Variante zu sein. Doch auch hier scheint das Rasseln mit den Säbeln weitaus wirkungsvoller zu sein als ihr Einsatz. Denn wenn ein Krieg ausbricht, dann werden die Verhandlungen enden, und es ist unklar, wer in welcher Position ist, wenn erneut Verhandlungen aufgenommen werden. Darum ist eine Kriegsdrohung deutlich besser als ein Krieg, wenn es um Verhandlungstaktiken geht. 
Auch die innenpolitischen Probleme Putins verlangen nicht nach einem handfesten Krieg. Diskussionen um innere Probleme kann man mit demonstrativen Kriegsvorbereitungen vermeiden, nicht mit einem Krieg. Um die Stammwählerschaft zu mobilisieren (auf alle anderen wird doch eh schon längst gepfiffen, falls das jemand noch nicht bemerkt hat) und rituellen Segen für weitere Gewalt gegen die Opposition zu bekommen - dafür braucht es sicher keinen Krieg als solchen, zumindest keinen realen. Die Leute wurden dazu erzogen, dem Fernseher zu vertrauen und sie werden leicht daran glauben, Putin habe auch ohne Krieg alle überlistet, oder der Krieg habe schon stattgefunden und mit einem weiteren Sieg für uns geendet.

\section{Das Feiglingsspiel}

In der Mathematik gibt es den Bereich der Spieltheorie. Beachtenswert ist da das Chicken Game, das in einer einfachen Variante so aussieht: Zwei Autofahrer jagen aufeinander zu, und wer als erstes der Gefahr ausweicht, der ist ein Feigling. Und wer nicht ausweicht, der gewinnt. Falls keiner ausweicht, können beide beim Unfall umkommen.

Damit der Gegenspieler garantiert als erstes ausweicht, ist es sinnvoll, vorab Leichtsinn oder gar Fatalismus zu demonstrieren: Der Gegner soll denken, dass dieser Dummkopf tatsächlich bereit ist zu sterben und den anderen mit ins Grab zu ziehen.

Genau dieses Spiel spielt Putin nun mit dem Westen. Auf der einen Seite gibt es ihn, den Diktator, der mit allen Mitteln demonstriert, dass ihn die Meinung irgendwelcher Unzufriedener im eigenen Land überhaupt nicht interessiert, der nicht vorhat, sich in irgendwelchen Wahlkämpfen zu behaupten, und sich deswegen auch egal was erlauben kann - sei es, bis zum Äußersten zu gehen und tatsächlich einen Krieg anzuzetteln, oder seien es Zugeständnisse. Auf der anderen Seite gibt es die Eliten des Westens und allen voran der USA, die sehr wohl abhängig sind von der öffentlichen Meinung im eigenen Land und voneinander.

Darin liegt anscheinend Putins größter Trumpf: Die gegenwärtige westliche Moral macht Krieg zu einer größeren Schmach als Feigheit. Das gibt den westlichen Herrschern die Möglichkeit, im letzten Moment vom
Pfad der Konfrontation abzuspringen und den Wählern zu sagen: Wolltet ihr etwa wirklich einen Krieg mit Russland wegen irgendeiner Ukraine?

Genau darauf spekuliert Putin, wie es scheint: dass der Westen im Augenblick der größten Anspannung einen Rückzieher macht und sich nicht nur damit abfindet, dass die Krim russisch ist, sondern auch damit, dass die Ukraine zur russischen Einflusssphäre gehört und man sich in innere Angelegenheiten Russlands eben keinesfalls einzumischen hat.

\section{Drohender Kontrollverlust}

Wenn der Welt und uns allen etwas droht, dann, dass die massenhafte Konzentration von bewaffneten Menschen und Militärtechnik an einem Ort zu einer Entwicklung der Ereignisse führen kann, die von niemandem mehr beherrscht wird. Putin, Biden und Selensky versuchen vielleicht globale Probleme zu lösen. Aber dann sind da ja auch noch die Offiziere und Generäle der Armeen und Geheimdienste, für die Krieg ein absolut legitimes Mittel zum Aufstieg auf der Karriereleiter ist. Und schließlich gibt es einfach auch noch Abenteurer, Sadisten, Beutemacher und andere Halunken verschiedenster Couleur, denen der Krieg eine Chance bietet, ihre alles andere als globalen Probleme zu lösen.

Der Krieg könnte wie zufällig beginnen - als Antwort auf eine weitere Provokation, als lokale Operation, als Ergebnis einer falschen Lageeinschätzung oder als bewusste Manipulation von jemandem, dem persönlich an einer Eskalation gelegen ist. Den ersten Schritt könnte auch die Ukraine machen, denn auch für deren Regierung wäre das eine völlig erklärbare Strategie: Auf einen Krieg kann man vieles abschieben und Probleme hat Selensky genug. Kurz gesagt, momentan könnte alles mögliche passieren, durch das Verschulden von einer beliebigen Seite. Aber wenn ein Krieg ausbricht, dann ist das nie zufällig, sondern die gesetzmäßige Folge von dem, was in den vergangenen Jahren passiert ist. Und dennoch bleibt die Hoffnung, dass es nicht zu einem großen Krieg kommt. Moderne Kommunikationsmittel bieten die Chance, dass im letzten Moment trotz allem der Befehl ankommt, der heißt: Entwarnung.

Der Text erschien am 07.04.202 in der Online-Zeitung "Republic und wurde von Dekoder übersetzt und in einer gekürzten Fassung am 08.04.2021 veröffentlicht.

Das russischsprachige Original des vorliegenden Beitrags ist online verfügbar unter https://republic.ru/posts/100068, die deutsche Übersetzung unter https://www.dekoder.org/de/article/mobilisierung-militaer-donbass-ukrainekrise.

Die Redaktion der Ukraine-Analysen freut sich, dekoder.org als langfristigen Partner gewonnen zu haben. Wir danken unserem Partner dekoder, Republic und Fjodor Krascheninnikow für die Erlaubnis zum Nachdruck. 


\title{
Die Verbreitung von Covid-19 in der Ukraine (Stand: 17. Mai 2021)
}

\author{
Grafik 1: Ausbreitung von Covid-19 in der Ukraine (tägliche Fallzahlen, 1. März 2020 - 17. Mai 2021)
}

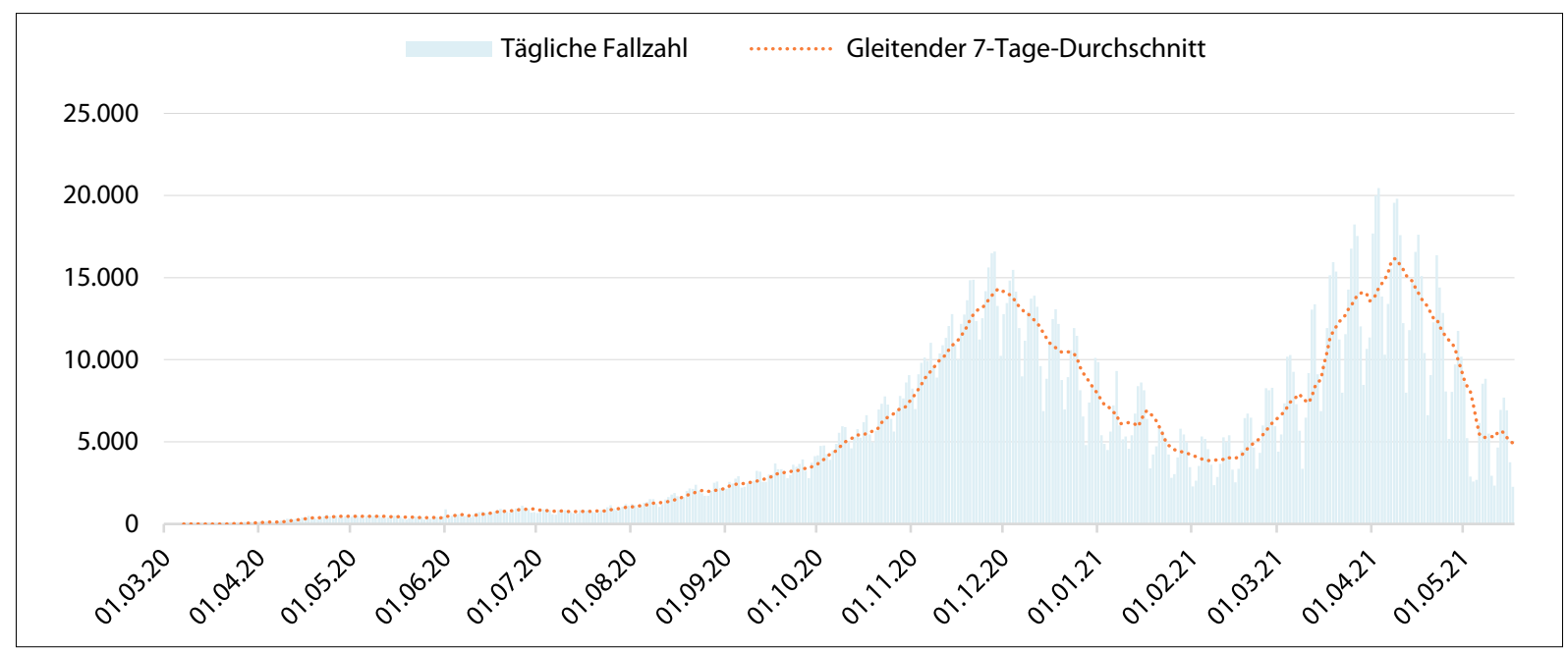

Die angegebenen Zahlen und Daten basieren auf Angaben der US-amerikanischen Johns Hopkins Universität, die sich auf offizielle Angaben des Nationalen Rats für Sicherheit und Verteidigung der Ukraine beruft (https://covid19.rnbo.gov.ua/). Die Zahlen geben die öffentlich kommunizierte Einschätzung der epidemiologischen Lage in der Ukraine wieder. Die Statistik ist von mehreren Faktoren abhängig, u. a. vom Testniveau, das in der Ukraine im Vergleich mit anderen europäischen Staaten als eher niedrig gilt.

Quelle: Johns Hopkins Universität. Stand: 17.05.2021, 11:20 Uhr MESZ https://coronavirus.jhu.edu/map.html; https://github.com/ CSSEGISandData/5COVID-19/blob/master/csse_covid_19_data/csse_covid_19_time_series/time_series_covid19_confirmed_global.csv

Tabelle 1:Ausbreitung von Covid-19 in der Ukraine (Fälle, 29. April - 17. Mai 2021)

\begin{tabular}{|c|c|c|}
\hline Datum & Gesamtzahl der Fälle & Tägliche Fallzahl \\
\hline 29.04 .21 & 2.113 .880 & 11.750 \\
30.04 .21 & 2.124 .070 & 10.190 \\
01.05 .21 & 2.132 .742 & 8.672 \\
02.05 .21 & 2.137 .959 & 5.217 \\
03.05 .21 & 2.140 .838 & 2.879 \\
04.05 .21 & 2.143 .427 & 2.589 \\
05.05 .21 & 2.146 .121 & 2.694 \\
06.05 .21 & 2.152 .280 & 6.159 \\
07.05 .21 & 2.160 .809 & 8.529 \\
08.05 .21 & 2.169 .650 & 8.841 \\
\hline
\end{tabular}

\begin{tabular}{|c|c|c|}
\hline Datum & Gesamtzahl der Fälle & Tägliche Fallzahl \\
\hline 09.05 .21 & 2.175 .151 & 5.501 \\
10.05 .21 & 2.178 .095 & 2.944 \\
11.05 .21 & 2.180 .429 & 2.334 \\
12.05 .21 & 2.185 .088 & 4.659 \\
13.05 .21 & 2.192 .022 & 6.934 \\
14.05 .21 & 2.199 .708 & 7.686 \\
15.05 .21 & 2.206 .627 & 6.919 \\
16.05 .21 & 2.210 .375 & 3.748 \\
17.05 .21 & 2.212 .635 & 2.260 \\
\hline
\end{tabular}

Für die Zahlen vom 01.03.2020-28.04.2021 siehe die Statistik "Die Verbreitung von Covid-19 in der Ukraine« in den Ukraine-Analysen 233-250.

Die angegebenen Zahlen und Daten basieren auf Angaben der US-amerikanischen Johns Hopkins Universität, die sich auf offizielle Angaben des Nationalen Rats für Sicherheit und Verteidigung der Ukraine beruft (https://covid19.rnbo.gov.ua/). Die Zahlen geben die öffentlich kommunizierte Einschätzung der epidemiologischen Lage in der Ukraine wieder. Die Statistik ist von mehreren Faktoren abhängig, u. a. vom Testniveau, das in der Ukraine im Vergleich mit anderen europäischen Staaten als eher niedrig gilt.

Quelle: Johns Hopkins Universität. Stand: 17.05.2021, 11:20 Uhr MESZ https://coronavirus.jhu.edu/map.html; https://github.com/CSSEGISandData/ COVID-19/blob/master/csse_covid_19_data/csse_covid_19_time_series/time_series_covid19_confirmed_global.csv 
Grafik 2: Todesfälle durch Covid-19 in der Ukraine (tägliche Todesfälle, 1. März 2020 - 17. Mai 2021)

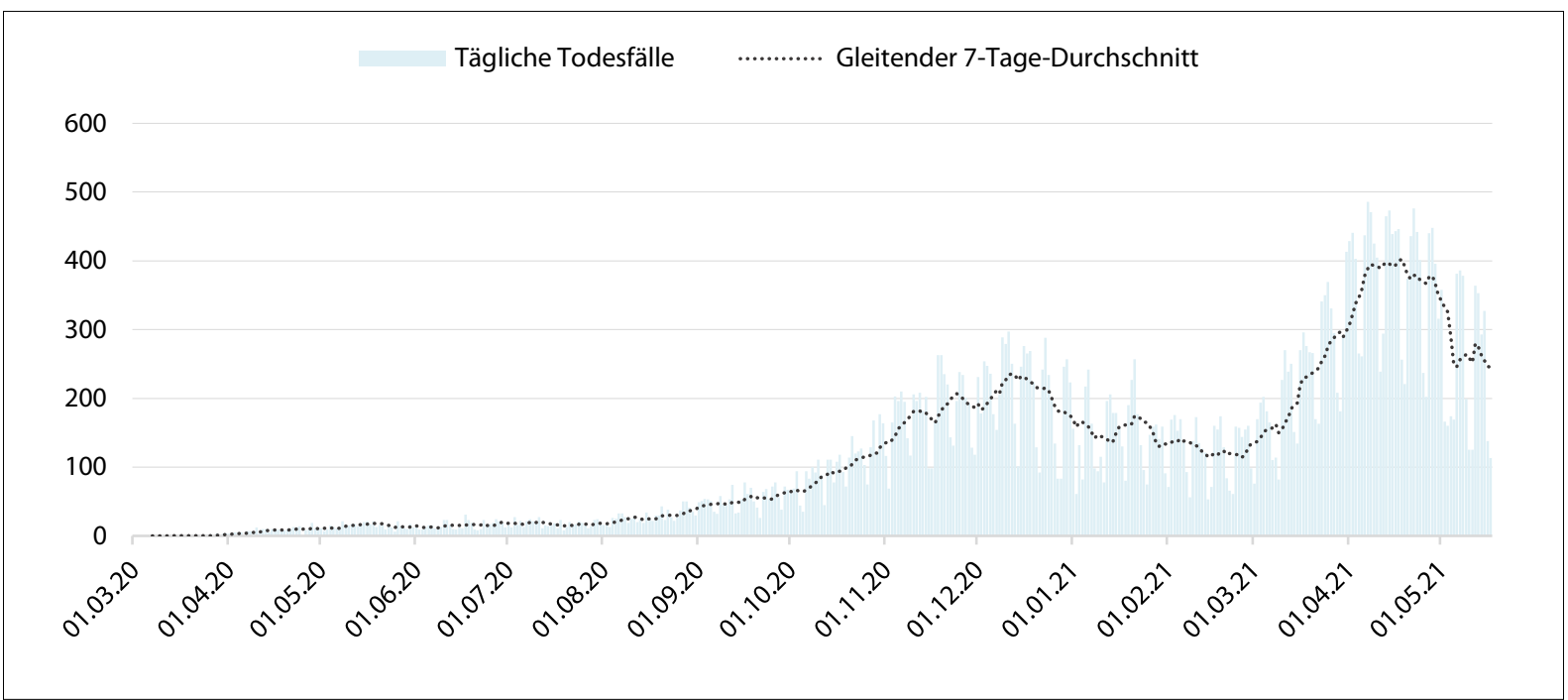

Die angegebenen Zahlen und Daten basieren auf Angaben der US-amerikanischen Johns Hopkins Universität, die sich auf offizielle Angaben des Nationalen Rats für Sicherheit und Verteidigung der Ukraine beruft (https://covid19.rnbo.gov.ua/). Die Zahlen geben die öffentlich kommunizierte Einschätzung der epidemiologischen Lage in der Ukraine wieder. Die Statistik ist von mehreren Faktoren abhängig, u. a. vom Testniveau, das in der Ukraine im Vergleich mit anderen europäischen Staaten als eher niedrig gilt.

Quelle: Johns Hopkins Universität. Stand: 17.05.2021, 11:20 Uhr MESZ https://coronavirus.jhu.edu/map.html; https://github.com/CSSEGISandData/ COVID-19/blob/master/csse_covid_19_data/csse_covid_19_time_series/time_series_covid19_deaths_global.csv

Tabelle 2: Todesfälle durch Covid-19 in der Ukraine (29. April - 17. Mai 2021)

\begin{tabular}{|c|c|c|c|c|c|}
\hline Datum & $\begin{array}{l}\text { Gesamtzahl der } \\
\text { Todesfälle }\end{array}$ & Tägliche Todesfälle & Datum & $\begin{array}{c}\text { Gesamtzahl der } \\
\text { Todesfälle }\end{array}$ & Tägliche Todesfälle \\
\hline 29.04.21 & 45.607 & 396 & 09.05.21 & 48.294 & 199 \\
\hline 30.04 .21 & 45.923 & 316 & 10.05 .21 & 48.419 & 125 \\
\hline 01.05 .21 & 46.281 & 358 & 11.05 .21 & 48.544 & 125 \\
\hline 02.05 .21 & 46.447 & 166 & 12.05 .21 & 48.908 & 364 \\
\hline 03.05 .21 & 46.607 & 160 & 13.05 .21 & 49.261 & 353 \\
\hline 04.05 .21 & 46.781 & 174 & 14.05 .21 & 49.554 & 293 \\
\hline 05.05 .21 & 46.950 & 169 & 15.05 .21 & 49.881 & 327 \\
\hline 06.05 .21 & 47.331 & 381 & 16.05 .21 & 50.019 & 138 \\
\hline 07.05 .21 & 47.717 & 386 & 17.05 .21 & 50.132 & 113 \\
\hline 08.05 .21 & 48.095 & 378 & & & \\
\hline
\end{tabular}

Für die Zahlen vom 01.03.2020-28.04.2021 siehe die Statistik "Die Verbreitung von Covid-19 in der Ukraine« in den Ukraine-Analysen 233-250.

Die angegebenen Zahlen und Daten basieren auf Angaben der US-amerikanischen Johns Hopkins Universität, die sich auf offizielle Angaben des Nationalen Rats für Sicherheit und Verteidigung der Ukraine beruft (https://covid19.rnbo.gov.ua/). Die Zahlen geben die öffentlich kommunizierte Einschätzung der epidemiologischen Lage in der Ukraine wieder. Die Statistik ist von mehreren Faktoren abhängig, u. a. vom Testniveau, das in der Ukraine im Vergleich mit anderen europäischen Staaten als eher niedrig gilt.

Quelle: Johns Hopkins Universität. Stand: 17.05.2021, 11:20 UhrMESZ https://coronavirus.jhu.edu/map.html; https://github.com/CSSEGISandData/ COVID-19/blob/master/csse_covid_19_data/csse_covid_19_time_series/time_series_covid19_deaths_global.csv 
Grafik 3: Regionale Verteilung der Covid-19-Infektionen (Stand: 17. Mai 2021)

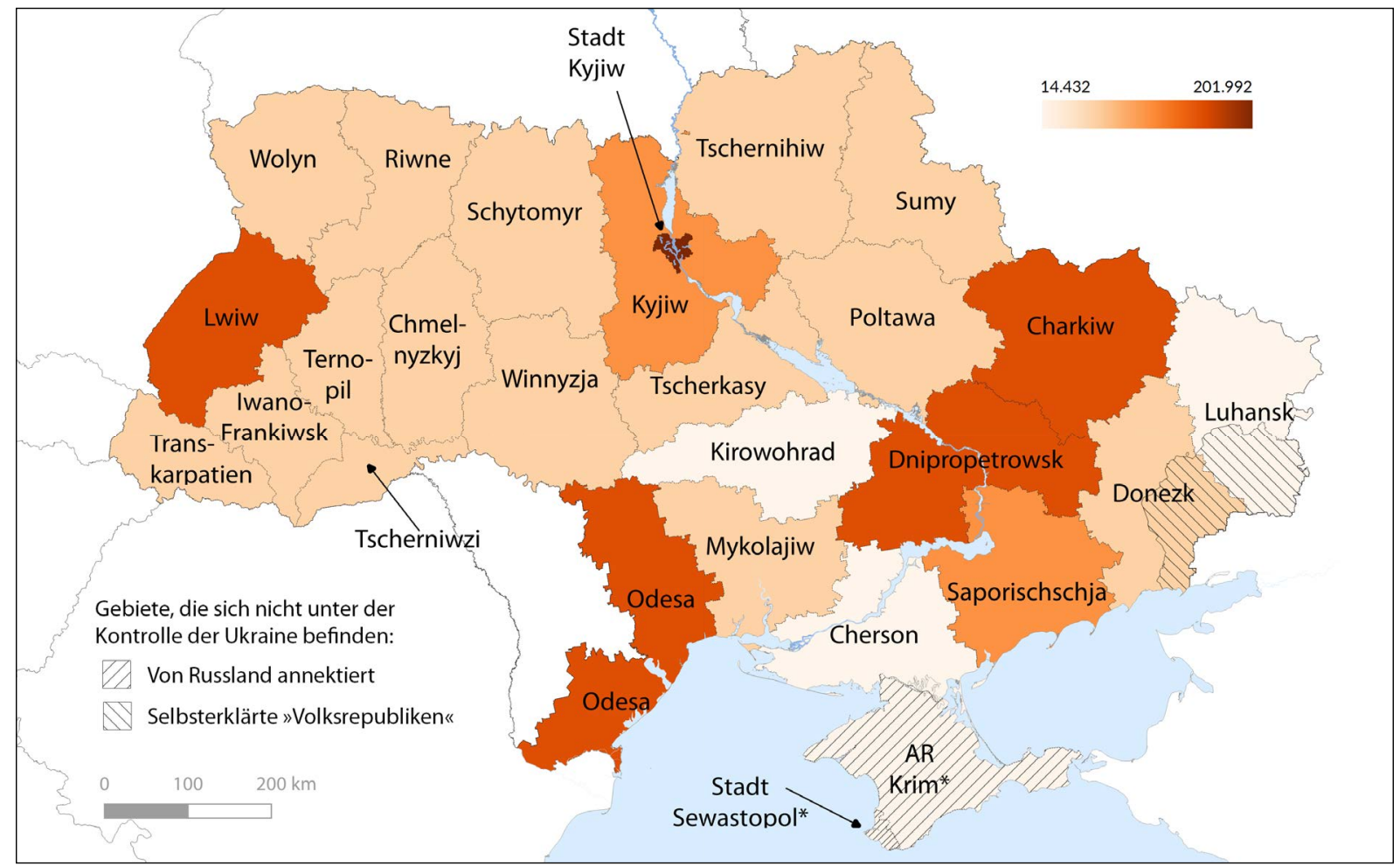

* Inoffizielle Daten; Datenquelle: https://www.pravda.com.ua/cdn/covid-19/cpa/, Stand: 17.05.2021 08:12 Uhr.

Karte erstellt von der Forschungsstelle Osteuropa an der Universität Bremen in QGIS mit Geodaten von https://www.openstreetmap.org.

\section{Grafik 4: Regionale Verteilung der Todesfälle durch Covid-19-Infektionen (Stand: 17. Mai 2021)}

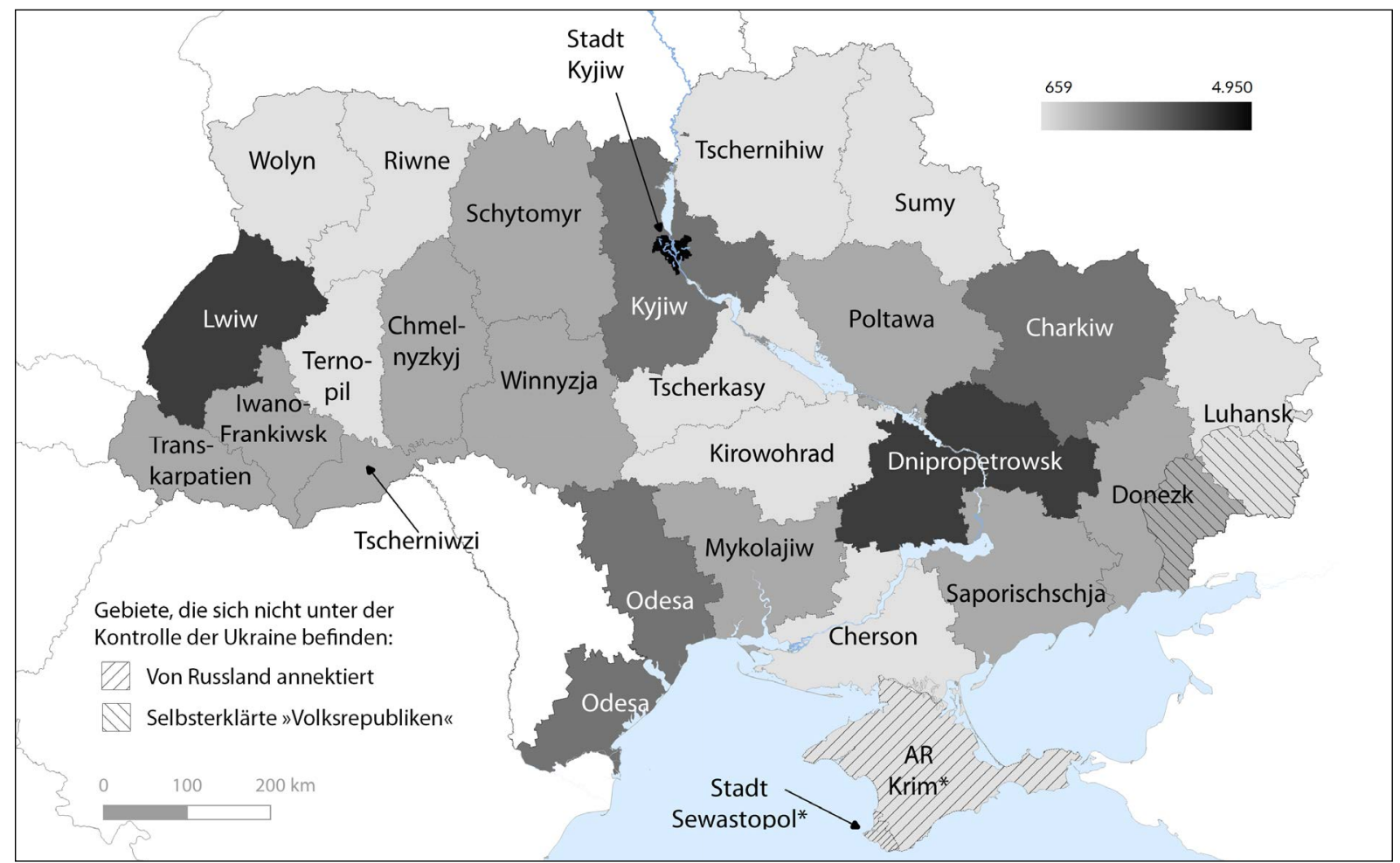

*Inoffizielle Daten; Datenquelle: https://www.pravda.com.ua/cdn/covid-19/cpa/, Stand: 17.05.2021 08:12 Uhr.

Karte erstellt von der Forschungsstelle Osteuropa an der Universität Bremen in QGIS mit Geodaten von https://www.openstreetmap.org. 
Grafik 5: Regionale Verteilung der Covid-19-Infektionen und der Todesfälle durch Covid-19-Infektionen (Stand: 17. Mai 2021)

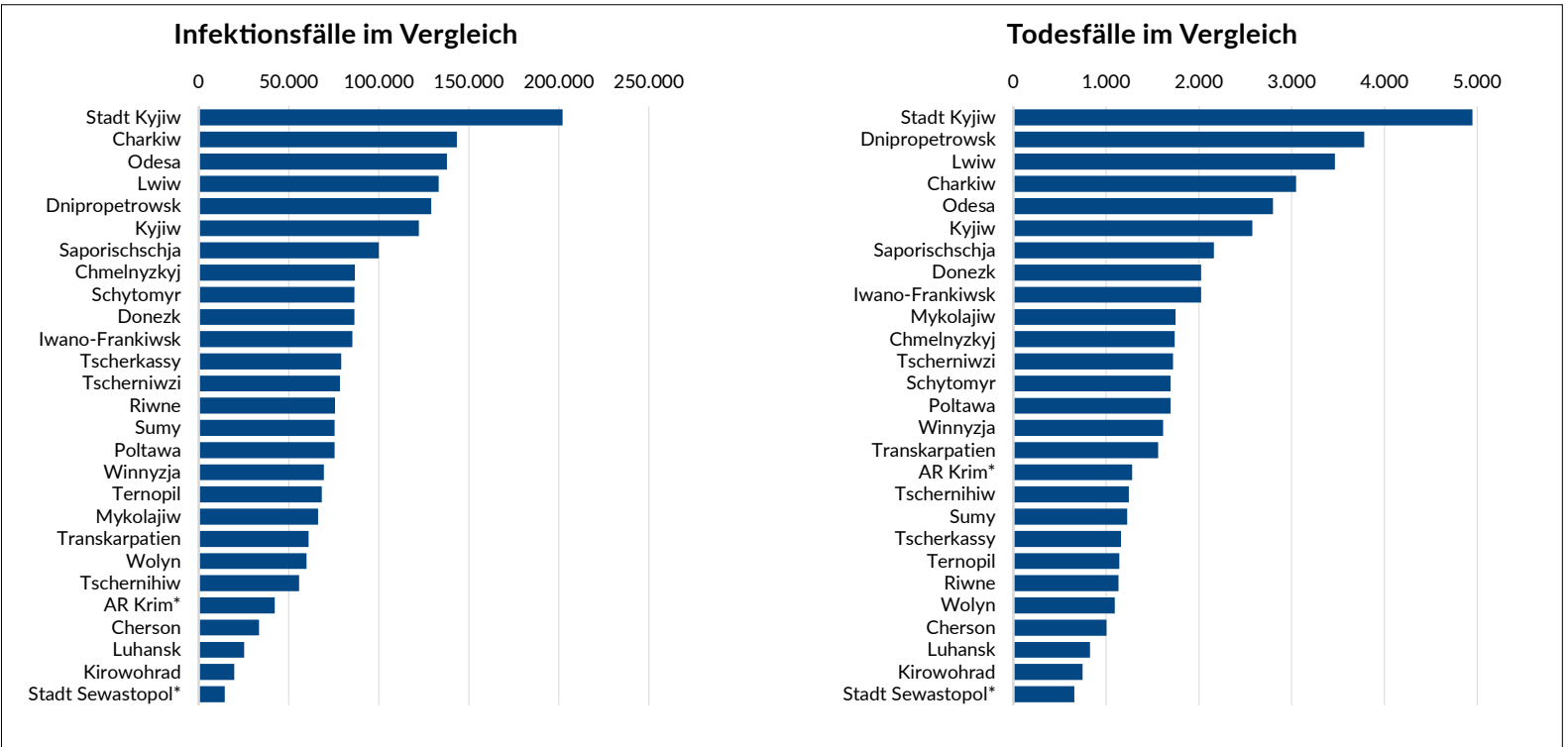

*Inoffizielle Daten; Datenquelle: https://www.pravda.com.ua/cdn/covid-19/cpa/, Stand: 17.05.2021 08:12 Uhr.

Tabelle 3: Regionale Verteilung der Covid-19-Infektionen und der Todesfälle durch Covid-19-Infektionen (Stand: 17. Mai 2021)

\begin{tabular}{|c|c|c|}
\hline Region & Fälle & Todesfälle \\
\hline Charkiw & 143.316 & 3.050 \\
\hline Cherson & 33.380 & 1.004 \\
\hline Chmelnyzkyj & 86.599 & 1.738 \\
\hline Dnipropetrowsk & 129.201 & 3.781 \\
\hline Donezk & 86.421 & 2.026 \\
\hline Iwano-Frankiwsk & 85.301 & 2.025 \\
\hline Kirowohrad & 19.694 & 744 \\
\hline Kyjiw & 122.242 & 2.577 \\
\hline Stadt Kyjiw & 201.992 & 4.950 \\
\hline Luhansk & 25.285 & 828 \\
\hline Lwiw & 133.304 & 3.468 \\
\hline Mykolajiw & 66.329 & 1.747 \\
\hline Odesa & 137.917 & 2.797 \\
\hline Poltawa & 75.449 & 1.693 \\
\hline Riwne & 75.714 & 1.135 \\
\hline Saporischschja & 100.079 & 2.164 \\
\hline Schytomyr & 86.509 & 1.694 \\
\hline Sumy & 75.558 & 1.228 \\
\hline Ternopil & 68.389 & 1.142 \\
\hline Transkarpatien & 60.959 & 1.560 \\
\hline Tscherkassy & 79.038 & 1.159 \\
\hline Tschernihiw & 55.624 & 1.244 \\
\hline Tscherniwzi & 78.432 & 1.723 \\
\hline Winnyzja & 69.523 & 1.615 \\
\hline Wolyn & 59.745 & 1.092 \\
\hline AR Krim* & 42.079 & 1.282 \\
\hline Stadt Sewastopol* & 14.432 & 659 \\
\hline
\end{tabular}

*Inoffizielle Daten; Datenquelle: https://www.pravda.com.ua/cdn/covid-19/cpa/, Stand: 17.05.2021 08:12 Uhr. 
Grafik 6: Covid-19-Quarantänezonen (Stand: 16. Mai 2021, Daten bis zum 15. Mai 2021)

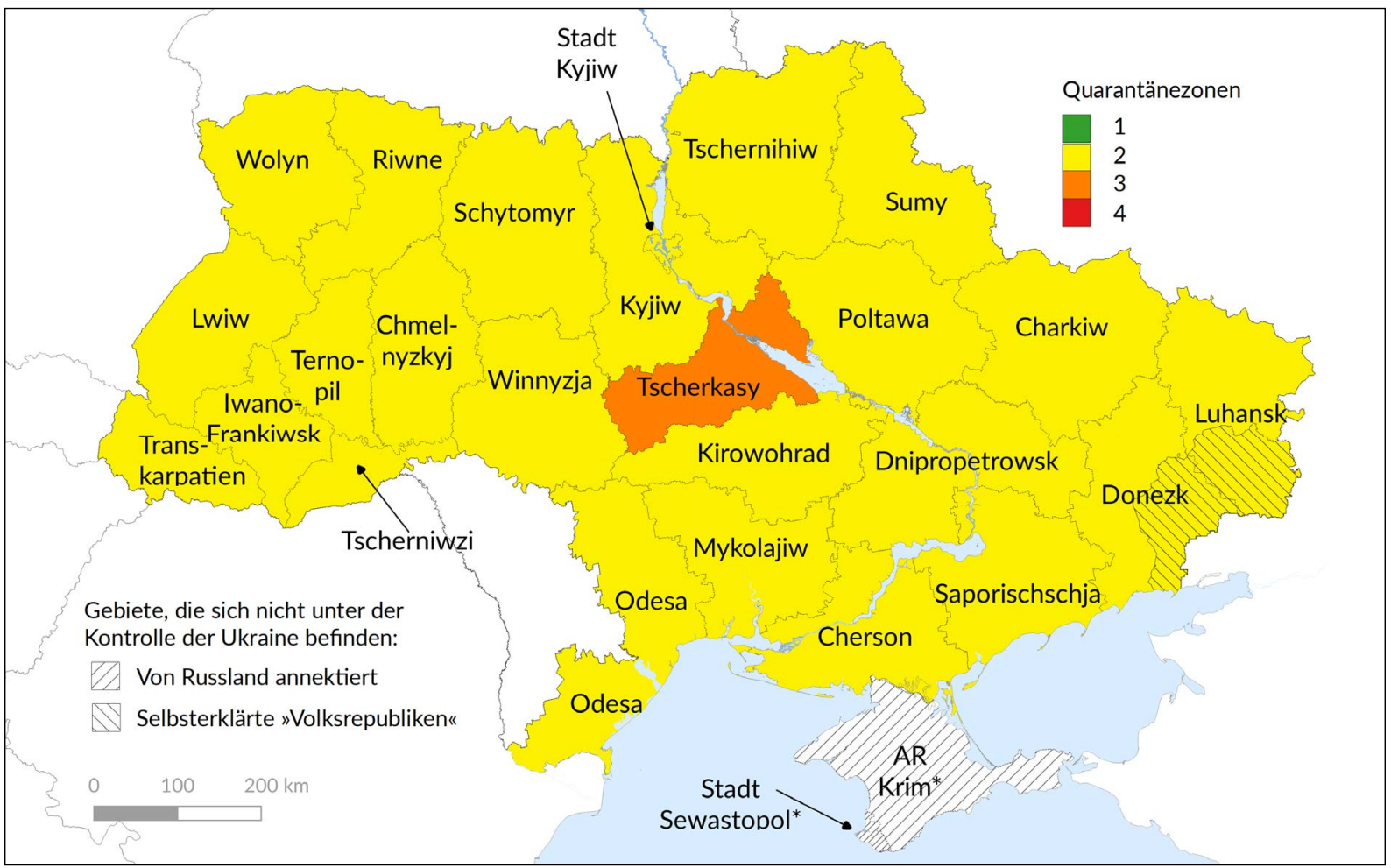

* Keine Daten; Datenquelle: https://moz.gov.ua/uploads/6/30576-15 05 2021.pdf, Stand: 16.05.2021.

Karte erstellt von der Forschungsstelle Osteuropa an der Universität Bremen in QGIS mit Geodaten von https://www.openstreetmap.org.

\section{Covid-19-Chronik, 26. April - 09. Mai 2021}

\begin{tabular}{|l|l|}
\hline 26.04.2021 & $\begin{array}{l}\text { Gesundheitsminister Maksym Stepanow teilt mit, dass aktuell 52 Prozent der Krankenhausbetten in der } \\
\text { Ukraine mit Covid-19 Patienten belegt seien. Die höchste Auslastung mit 71 Prozent gebe es in der Region } \\
\text { Chmelnyzkyj, so der Minister. }\end{array}$ \\
\hline 26.04.2021 & Die Region Lwiw verlässt die »rote« Zone und kann die Covid-19-Qurantäneschränkungen lockern. \\
\hline 27.04.2021 & $\begin{array}{l}\text { Laut Gesundheitsminister Maksym Stepanow verbessert sich die Covid-19 Lage im Land. Wurden Anfang } \\
\text { April noch bis zu 20.000 tägliche Neuansteckungen verzeichnet, sind es aktuell ca. 12.000. }\end{array}$ \\
\hline 28.04.2021 & $\begin{array}{l}\text { Die Ukraine und die Weltbank vereinbaren einen Kredit i.H.v. 89 Mio. US-Dollar zur Bekämpfung der Coro- } \\
\text { navirus-Pandemie. Das Geld ist vorgesehen für mehr Impfstoffe, neue Kühllagereinrichtungen und die Aus- } \\
\text { bildung medizinischen Personals. Der Kreditvertrag soll am 11. Mai in Washington unterzeichnet werden. }\end{array}$ \\
$\begin{array}{l}\text { Der Bürgermeister von Kyjiw, Witalij Klytschko, teilt mit, dass zum 1. Mai die Quarantäne-Beschränkungen } \\
\text { infolge der Covid-19-Pandemie teilweise gelockert werden. Kyjiw verlasse die »rote«Zone und Restaurants und } \\
\text { Geschäfte dürfen wieder öffnen, der öffentliche Nahverkehr soll uneingeschränkt genutzt werden dürfen und } \\
\text { am 5. Mai sollen Schulen und Kindergärten wieder öffnen. Die ukrainische Hauptstadt wurde am 20. März } \\
\text { zur »roten« Zone erklärt und ein strenger Lockdown trat in Kraft. }\end{array}$ \\
\hline 28.04.2021 & Mit 70.469 Impfungen gegen Covid-19 an einem Tag verzeichnet die Ukraine einen neuen Rekord. \\
\hline
\end{tabular}




\begin{tabular}{|c|c|}
\hline 29.04 .2021 & $\begin{array}{l}\text { Gesundheitsminister Maksym Stepanow teilt mit, dass am 30. April } 500.000 \text { weitere Dosen des CoronaVac } \\
\text { Impfstoffs gegen das Coronavirus eintreffen sollen. Insgesamt erhält die Ukraine 1,9 Mio. Dosen des chinesi- } \\
\text { schen Herstellers Sinovac. }\end{array}$ \\
\hline 01.05 .2021 & $\begin{array}{l}\text { Neben der Hauptstadt Kyjiw verlässt auch die Region Mykolajiw die »rote« Covid-19-Zone und lockert die } \\
\text { Quarantänebeschränkungen. }\end{array}$ \\
\hline 01.05 .2021 & $\begin{array}{l}\text { Gesundheitsminister Maksym Stepanow verkündet, dass die Ukraine einen Vertrag über weitere } 10 \text { Millio- } \\
\text { nen Dosen des Pfizer-BioNTech Impfsoffs gegen das Coronavirus abgeschlossen habe. Bereits im April hatte } \\
\text { sich die Ukraine die gleiche Menge an Impfstoff des Herstellers gesichert. Im Mai werden rund eine Millionen } \\
\text { Pfizer-Dosen erwartet, der Großteil (15 Mio. Dosen) wird jedoch erst im letzten Quartal des Jahres geliefert. }\end{array}$ \\
\hline 01.05 .2021 & $\begin{array}{l}\text { Im April wurden in der Ukraine weniger als } 800.000 \text { Menschen gegen Covid- } 19 \text { geimpft - etwa ein Viertel } \\
\text { von dem, was die Regierung angekündigt hatte. Fehlende Impfdosen sind der wesentliche limitierende Faktor. }\end{array}$ \\
\hline 02.05 .2021 & $\begin{array}{l}\text { Ab heute werden ausländische Reisende aus Indien wegen der besorgniserregenden Lage dort nicht mehr in } \\
\text { die Ukraine gelassen. Indien, wo wich eine besonders aggressive Variante des Coronavirus stark ausbreitet, ver- } \\
\text { zeichnet aktuell die höchsten Covid-19-Neuinfektionen weltweit. }\end{array}$ \\
\hline 02.05 .2021 & Aktuell gelten noch sieben ukrainische Regionen als»rote« Zonen mit den strengsten Covid-19-Beschränkungen. \\
\hline 05.05 .2021 & Die Region Schytomyr wird zur »orangen" Zone erklärt und lockert die Covid-19-Beschränkungen. \\
\hline 05.0 & $\begin{array}{l}\text { Laut Informationen des "Gesundheitsministeriums der Volksrepublik Donezk» sind bisher } 33.734 \text { Menschen } \\
\text { in der nicht anerkannten Republik an Covid-19 erkrankt; } 2.551 \text { Menschen sind daran gestorben. Die Zah- } \\
\text { len können jedoch nicht unabhängig überprüft werden und die Dunkelziffer gilt als hoch. Der Anführer der } \\
\text { "Volksrepublik«, Denys Puschilin, gibt derweil bekannt, dass bis zum Jahresende eine Million Menschen } \\
\text { geimpft werden sollen. }\end{array}$ \\
\hline 06.05. & $\begin{array}{l}\text { Die Regionen Charkiw, Tschernihiw und Chmelnyzkyj werden zu »orangen« Zonen und lockern ihre } \\
\text { Covid-19-Beschränkungen. }\end{array}$ \\
\hline 06.05 . & $\begin{array}{l}\text { Das ukrainische Gesundheitsministerium plant, bis zum 1. Juli „Covid-Zertifikate« einzuführen: interne Rei- } \\
\text { sedokumente, die Informationen über Impfung, negative PCR-Tests oder die bestätigte Genesung von Covid- } \\
19 \text { enthalten. }\end{array}$ \\
\hline 07.05 .2021 & $\begin{array}{l}\text { Gesundheitsminister Maksym Stepanow verkündet, die dritte Welle der Coronavirus-Pandemie sei in der } \\
\text { Ukraine überstanden. Sie sei zwar die tödlichste gewesen, dennoch sei die Ukraine besser und mit weniger } \\
\text { Opfern durch die Dritte Welle gekommen als erwartet. }\end{array}$ \\
\hline 07.05 .2021 & $\begin{array}{l}\text { Laut Schätzungen des Institute of Health Metrics and Evaluation (IHME) der Universität Washington sind } \\
\text { durch das Coronavirus in der Ukraine bisher } 138.507 \text { Menschen gestorben, während die offizielle Statistik } \\
46.737 \text { Corona-Tote aufweist. }\end{array}$ \\
\hline 08.05 .2021 & $\begin{array}{l}\text { Aktuell gibt es keine »rote"Covid-19-Quarantänezone mehr in der Ukraine. Sieben Regionen gelten als »orange» } \\
\text { Zonen mit der zweithöchsten Quarantäne-Stufe, der Rest des Landes sind "gelbe« Zonen. }\end{array}$ \\
\hline 09.05 .2021 & $\begin{array}{l}\text { Zehn Tage später als erwartet erhält die Ukraine eine Tranche mit } 500.000 \text { Impfdosen des CoronaVac Impf- } \\
\text { stoffs zur Bekämpfung der Coronavirus-Pandemie. Damit hat die Ukraine 1,2 Mio. der insgesamt 1,9 Mio. } \\
\text { bestellten Impfdosen des chinesischen Herstellers Sinovac Biotech erhalten. }\end{array}$ \\
\hline 09.05 .2021 & $\begin{array}{l}\text { Laut Experten des staatlichen ukrainischen Gesundheitszentrums müssen in der Ukraine täglich etwa } 100.000 \\
\text { Menschen gegen das Coronavirus geimpft werden, um bis zum Jahresende } 70 \text { Prozent der Bevölkerung zu imp- } \\
\text { fen und damit eine Herdenimmunität zu erreichen. Tatsächlich liegt die Impfquote in der Ukraine aktuell deut- } \\
\text { lich niedriger mit maximal } 70.000 \text { Impfungen an einem Tag. }\end{array}$ \\
\hline
\end{tabular}

Zusammengestellt von Dr. Eduard Klein 


\section{April - 09. Mai 2021}

\begin{tabular}{|c|c|}
\hline 26.04 .2021 & $\begin{array}{l}\text { Laut dem Forschungsinstitut SIPRI beliefen sich die Verteidigungsausgaben der Ukraine im Jahr } 2020 \text { auf ins- } \\
\text { gesamt 5,9 Mrd. US-Dollar. Damit nimmt die Ukraine im internationalen Vergleich Platz } 34 \text { ein. }\end{array}$ \\
\hline 26.04 .2021 & $\begin{array}{l}\text { Während eines Besuchs im Kernkraftwerk Tschernobyl anlässlich des 35. Jahrestags der Nuklearkatastrophe } \\
\text { gibt Präsident Wolodymyr Selenskyj bekannt, dass er seinen Stabschef damit beauftragt habe, mögliche Termine } \\
\text { und Orte für ein Gipfeltreffen mit dem russischen Präsidenten Wladimir Putin zu finden. Er hoffe außerdem, } \\
\text { dass es während der anstehenden orthodoxen Osterfeiertage keine Kämpfe im Donbas geben werde-zumindest } \\
\text { die ukrainische Seite habe alles dafür getan, so Selenskyj. Im April sind } 13 \text { ukrainische Soldaten an der Kon- } \\
\text { taktlinie gestorben, nachdem die Intensität der Kämpfe in den vergangenen Wochen wieder zugenommen hat. }\end{array}$ \\
\hline 26.04 .2021 & $\begin{array}{l}\text { Präsident Wolodymyr Selenskyj schlägt in einem Interview mit der Financial Times vor, die USA, Großbri- } \\
\text { tannien und Kanada in die Gespräche zum Donbas einzubinden, um dem stockenden Friedensprozess neue } \\
\text { Impulse zu geben. Der Pressesprecher des russischen Präsidenten Dmitri Peskow weist den Vorschlag als »alar- } \\
\text { mierendes Zeichen« zurück. Im Interview weist Selenskyj den Vorschlag des russischen Präsidenten Wladimir } \\
\text { Putin zurück, direkte Verhandlungen mit den Anführern der nicht anerkannten "Volksrepubliken« im Don- } \\
\text { bas zu führen. }\end{array}$ \\
\hline 26.04 .2021 & $\begin{array}{l}\text { Der französische Präsident Emmanuel Macron fordert in einem Telefonat mit dem russischen Präsidenten Wla- } \\
\text { dimir Putin diesen dazu auf, das russische Militär von der ukrainischen Grenze abzuziehen und die Waffen- } \\
\text { ruhe im Donbas einzuhalten. }\end{array}$ \\
\hline 27.04 .2021 & $\begin{array}{l}\text { Der Pressedienst der rechtsradikalen Partei »Nationalkorps« teilt mit, dass angesichts der aktuellen Bedrohung } \\
\text { durch Russland der "Nationalkorps« Verteidigungsbüros in allen Regionen des Landes aufbauen werde. In } \\
\text { Kyjiw und Odesa haben die Büros bereits ihre Arbeit aufgenommen. }\end{array}$ \\
\hline 28.04 .2021 & $\begin{array}{l}\text { Der Leiter des staatlichen Grenzdienstes Serhij Dejneko berichtet, dass laut dem ukrainischen Geheimdienst } \\
\text { Russland erst teilweise seine jüngst auf der Krim stationierten Truppen von der annektierten Halbinsel abge- } \\
\text { zogen habe. Was die Feldlager in der Region Woronesch betrifft, gebe es hingegen bisher noch gar keine Bewe- } \\
\text { gung, so Dejneko. }\end{array}$ \\
\hline 28.04 .2021 & $\begin{array}{l}\text { Das Ministerkabinett entlässt den Vorstandschef des staatlichen Energiekonzerns Naftohas Andrij Kobolew auf- } \\
\text { grund »unbefriedigender« Arbeit. Zu seinem Nachfolger wird der amtierende Energieminister Jurij Witrenko } \\
\text { ernannt. Einen Tag zuvor verkündete Naftohas, größter Steuerzahler der Ukraine, erstmals seit } 2015 \text { eine nega- } \\
\text { tive Bilanz: Unter anderem wegen der Covid-Pandemie machte Naftohas Verluste von } 684 \text { Mio. US-Dollar. Der } \\
\text { neue Vorstandschef Witrenko war lange Jahre im Top-Management von Naftohaz bis er sich Medienberichten } \\
\text { zufolge mit Kobolew überwarf und den Konzern } 2020 \text { verließ. Kobolew teilt aber mit, dass er nicht freiwillig } \\
\text { gegangen sei und erst aus den Medien von seiner Entlassung erfahren habe. International stößt die Entschei- } \\
\text { dung auf viel Kritik, da für die Entlassung nicht das Ministerkabinett, sondern der Aufsichtsrat zuständig ist } \\
\text { und die Ukraine damit Corporate Governance Regeln verletzt hat. }\end{array}$ \\
\hline 29.04 .2021 & $\begin{array}{l}\text { Das Parlament ernennt Herman Haluschtschenko, den Vizepräsidenten des staatlichen ukrainischen Atom- } \\
\text { konzerns Energoatom, zum neuen Energieminister. Haluschtschenko war seit } 2013 \text { bei Energoatom und stieg } \\
\text { im Mai } 2020 \text { zum Vizepräsidenten auf. Ukrainische Medien und NGOs sagen dem neuen Minister Verbin- } \\
\text { dungen zu Oligarchen nach. Unter seiner Obhut sollen die Oligarchen Rinat Achmetow und Ihor Kolomoj- } \\
\text { skyj von vergünstigten Strompreisen um bis zu } 40 \text { Prozent profitiert haben. }\end{array}$ \\
\hline 29.04 .2021 & $\begin{array}{l}\text { Die Abgeordneten des Europäischen Parlaments verabschieden einen Entschließungsantrag, der harte Konse- } \\
\text { quenzen von der EU fordert, sollte die militärische Aufrüstung Russlands an der Grenze zur Ukraine zu einer } \\
\text { Invasion der Ukraine führen. Dazu zählen unter anderem der sofortige Stopp der EU-Importe von Öl und Gas } \\
\text { aus Russland, der Ausschluss Russlands aus dem SWIFT-Zahlungssystem und das Einfrieren von Vermögens- } \\
\text { werten von russischen Oligarchen. }\end{array}$ \\
\hline 30.04 .2021 & $\begin{array}{l}\text { Der Naftohas-Aufsichtsrat teilt mit, dass er infolge der umstrittenen Entlassung von Vorstandschef Andrij } \\
\text { Kobolew zum 14. Mai geschlossen zurückzutreten werde. Die Kontroverse um die Entlassung Kobolews könnte } \\
\text { auch eine Verzögerung der Auszahlung von IWF-Krediten nach sich ziehen. Der Ökonom Hlib Wyschlyn- } \\
\text { skyj warnt, dass die Entlassung ein Zeichen dafür sein könnte, dass »die Regierung wichtige Staatsunterneh- } \\
\text { men wieder unter politische Kontrolle bringen will.» }\end{array}$ \\
\hline 01.05 .2021 & $\begin{array}{l}\text { Das südukrainische Krywyj Ryh führt als erste ukrainische Großstadt einen kostenlosen Nahverkehr ein. Mit } \\
\text { einer entsprechenden Fahrkarte, die bereits } 300.000 \text { Einwohner der Stadt erhalten haben, können alle Ange- } \\
\text { bote des ÖPNV kostenlos genutzt werden. }\end{array}$ \\
\hline
\end{tabular}




\begin{tabular}{|c|c|}
\hline 02.05 .2021 & $\begin{array}{l}\text { Die russische Nachrichtenagentur TASS berichtet, dass inzwischen } 530.000 \text { Menschen in den »Volksrepubli- } \\
\text { ken« russische Pässe erhalten haben sollen. Bis Ende des laufenden Jahres rechnet Russland mit einer Million } \\
\text { ausgestellten russischen Pässen an die Bewohner der beiden »Volksrepubliken« im Donbas. }\end{array}$ \\
\hline 03.05 .2021 & $\begin{array}{l}\text { Im neuen »Nations in Transit 2021« Bericht von Freedom House schneidet die Ukraine mit } 39 \text { von } 100 \text { mögli- } \\
\text { chen Punkten einen Punkt schlechter ab als im Vorjahr. Das Land gilt dem Ranking zufolge weiter als »hybri- } \\
\text { des Regime«. Hauptgrund für die leichte Verschlechterung ist das Justizsystem, das Reformen blockierte und } \\
\text { eine Verfassungskrise auslöste. Das im Zuge des Maidans geöffnete Reformfenster für Reformen und Korrup- } \\
\text { tionsbekämpfung schließe sich langsam, so der Bericht. }\end{array}$ \\
\hline 03.05 .2021 & $\begin{array}{l}\text { Präsident Wolodymyr Selenskyj trifft anlässlich des 230. Jahrestags der polnischen Verfassung seinen polni- } \\
\text { schen Amtskollegen Andrzej Duda in Warschau. Die Präsidenten unterschreiben eine gemeinsame Erklärung } \\
\text { über die Unterstützung Polens für den EU-Beitritt der Ukraine. Bereits im März hatte Selenskyj ein ähnliches } \\
\text { Dokument mit dem litauischen Präsidenten unterzeichnet. }\end{array}$ \\
\hline 03.05 .2021 & $\begin{array}{l}\text { Der stellvertretende Außenminister der Ukraine Jewhen Jenin berichtet, dass ukrainische Unternehmen, die } \\
\text { durch die russische Aggression im Donbas und die Annexion der Krim Eigentum und Erträge verloren haben, } \\
\text { bei mehr als } 12 \text { Handelsschiedsgerichten Klagen eingereicht haben, die sich auf Forderungen von ca. 4,5 Mrd. } \\
\text { US-Dollar belaufen. }\end{array}$ \\
\hline 05.05 .2021 & $\begin{array}{l}\text { Die Venedig-Kommission kritisiert die im Februar } 2021 \text { ins Parlament eingebrachte Justizreform von Präsi- } \\
\text { dent Selenskyj als nicht ausreichend und fordert, dass internationale Richter eine größere Rolle bei der Reform } \\
\text { der ukrainischen Justiz spielen sollten. }\end{array}$ \\
\hline 05.05 .2021 & $\begin{array}{l}\text { Der staatliche Energiekonzern Naftohas legt neue Geschäftszahlen vor, denen zufolge der Konzern im ersten } \\
\text { Quartal einen Gewinn von } 455 \text { Mio. US-Dollar erwirtschaftet hat. Ende April war der Vorstandschef von Naf- } \\
\text { tohas in einer umstrittenen Entscheidung des Ministerkabinetts entlassen worden, nachdem das Unternehmen } \\
\text { im Vorjahr Verlust gemacht hatte. }\end{array}$ \\
\hline 06.05 .2021 & $\begin{array}{l}\text { Die Nationalbank der Ukraine teilt mit, dass die größte Bank des Landes nach dem Ende der Coronavirus-Pan- } \\
\text { demie privatisiert werden soll. Der Staat will seinen Anteil im Bankensektor in den kommenden fünf Jahren von } \\
\text { aktuell ca. } 55 \text { Prozent auf } 25 \text { Prozent reduzieren. Die PrivatBank war 2016, wie viele anderen Banken auch, ver- } \\
\text { staatlicht worden, um sie infolge von jahrelanger Misswirtschaft und Korruption vor dem Kollaps zu bewahren. }\end{array}$ \\
\hline 06.05 .2021 & $\begin{array}{l}\text { Laut Forbes konnten } 76 \text { der } 100 \text { reichsten Ukrainer im vergangenen Jahr trotz der Covid-19-Pandemie ihre Ver- } \\
\text { mögen weiter steigern. Zusammen verfügen die } 100 \text { reichsten Menschen in der Ukraine 44,5 Mrd. US-Dollar, } \\
\text { eine Steigerung um mehr als ein Drittel im Vergleich zum Vorjahr, als der Wert 31,4 Mrd. US-Dollar betrug. In } \\
\text { diesem Jahr gab es } 14 \text { Neuzugänge in der Rangliste, die vor allem aus den Bereichen IT und Energie kommen. }\end{array}$ \\
\hline 06.05 .2021 & $\begin{array}{l}\text { US-Außenminister Anthony Blinken trifft bei seinem ersten Besuch in Europa in Kyjiw neben Präsident Wolo- } \\
\text { dymyr Selenskyj, Premierminister Denys Schmyhal, Außenminister Dmytro Kuleba und einigen Parlaments- } \\
\text { abgeordneten auch Antikorruptionsaktivisten. Im Zentrum des Besuchs stehen unter anderem Gespräche } \\
\text { über die Situation im Donbas, mögliche US-Waffenlieferungen an die Ukraine, die NATO-Ambitionen der } \\
\text { Ukraine sowie der Reformprozess des Landes, insbesondere der Stand der Korruptionsbekämpfung. Blinken } \\
\text { zufolge stehe die Ukraine "vor zwei Herausforderungen: einer von außen, durch Russland. Darüber hinaus gibt } \\
\text { es eine Bedrohung von innen, nämlich Korruption und Oligarchen, die ihre eigenen Interessen über die des } \\
\text { ukrainischen Volkes stellen«. Blinken betont die Unterstützung Washingtons für die Ukraine sowohl im Krieg } \\
\text { gegen die von Russland unterstützten »Volksrepubliken«im Donbas als auch im Kampf gegen die Korruption. }\end{array}$ \\
\hline 06.05 .2021 & $\begin{array}{l}\text { Im Gespräch mit US-Außenminister Anthony Blinken teilt der ukrainische Präsident Wolodymyr Selenskyj } \\
\text { mit, dass Russland zwar teilweise Truppen aus der Grenzregion zur Ukraine abgezogen habe, sich aber weiter- } \\
\text { hin rund } 75.000 \text { russische Soldaten in der Region aufhalten. }\end{array}$ \\
\hline 08.05 .2021 & $\begin{array}{l}\text { Während einer Reise in die Region Luhansk hält Präsident Wolodymyr Selenskyj eine Videokonferenz mit dem } \\
\text { Präsidenten der Republik Lettland, Egils Levits, ab. Als Ergebnis des Gesprächs unterzeichnen die Staatschefs } \\
\text { eine gemeinsame Erklärung über die europäische Perspektive der Ukraine. Das ist nach Litauen und Polen die } \\
\text { dritte derartige Erklärung, die Selenskyj mit einem EU-Staatsoberhaupt unterzeichnet. }\end{array}$ \\
\hline 09.05 .2021 & $\begin{array}{l}\text { Nach Angaben der Polizei nehmen landesweit mehr als } 54.000 \text { Menschen an über } 700 \text { kleineren Veranstal- } \\
\text { tungen anlässlich des } 76 \text {. Jahrestags des Endes des Zweiten Weltkriegs teil. Wegen der Coronavirus-Pandemie } \\
\text { sieht die Ukraine in diesem Jahr von großen offiziellen Veranstaltungen ab. }\end{array}$ \\
\hline
\end{tabular}

Die Chronik wird zeitnah erstellt und basiert ausschließlich auf im Internet frei zugänglichen Quellen. Die Redaktion bemüht sich, bei jeder Meldung die ursprüngliche Quelle eindeutig zu nennen. Aufgrund der großen Zabl von manipulierten und falschen Meldungen kann die Redaktion der Ukraine-Analysen keine Gewähr für die Richtigkeit der Angaben übernehmen. 


\section{Herausgeber:}

Forschungsstelle Osteuropa an der Universität Bremen

Deutsche Gesellschaft für Osteuropakunde e.V.

Deutsches Polen-Institut

Leibniz-Institut für Agrarentwicklung in Transformationsökonomien

Leibniz-Institut für Ost- und Südosteuropaforschung

Zentrum für Osteuropa- und internationale Studien (ZOiS) gGmbH

\section{Redaktion:}

Dr. Eduard Klein (verantwortlich)

Chronik: Dr. Eduard Klein

Satz: Matthias Neumann

\section{Wissenschaftlicher Beirat:}

Dr. Kseniia Gatskova, Leibniz-Institut für Ost- und Südosteuropaforschung Regensburg

Prof. Dr. Guido Hausmann, Leibniz-Institut für Ost- und Südosteuropaforschung Regensburg

Dr. Susan Stewart, Stiftung Wissenschaft und Politik, Berlin

Dr. Susann Worschech, Europa-Universität Viadrina, Frankfurt/0.

Die Meinungen, die in den Ukraine-Analysen geäußert werden, geben ausschließlich die Auffassung der Autoren wieder.

Abdruck und sonstige publizistische Nutzung sind nach Rücksprache mit der Redaktion gestattet.

Ukraine-Analysen-Layout: Cengiz Kibaroglu, Matthias Neumann und Michael Clemens

Alle Ausgaben der Ukraine-Analysen sind mit Themen- und Autorenindex archiviert unter www.laender-analysen. de

Die Ukraine-Analysen werden im Rahmen eines Lizenzvertrages in das Internetangebot der Bundeszentrale für politische Bildung (www.bpb.de) aufgenommen.

ISSN 1862-555X @ 2021 by Forschungsstelle Osteuropa an der Universität Bremen, Deutsche Gesellschaft für Osteuropakunde e.V., Deutsches Polen-Institut, Leibniz-Institut für Agrarentwicklung in Transformationsökonomien, Leibniz-Institut für Ost- und Südosteuropaforschung, Zentrum für Osteuropa- und internationale Studien (ZOiS) gGmbH Forschungsstelle 0steuropa • Länder-Analysen • Klagenfurter Str. 8 • 28359 Bremen • Telefon: +49 421-218-69600 • Telefax: +49 421-218-69607 e-mail: laender-analysen@uni-bremen.de•Internet-Adresse: http://www.laender-analysen.de/ukraine/ 
ÄNDER-ANALYSEN

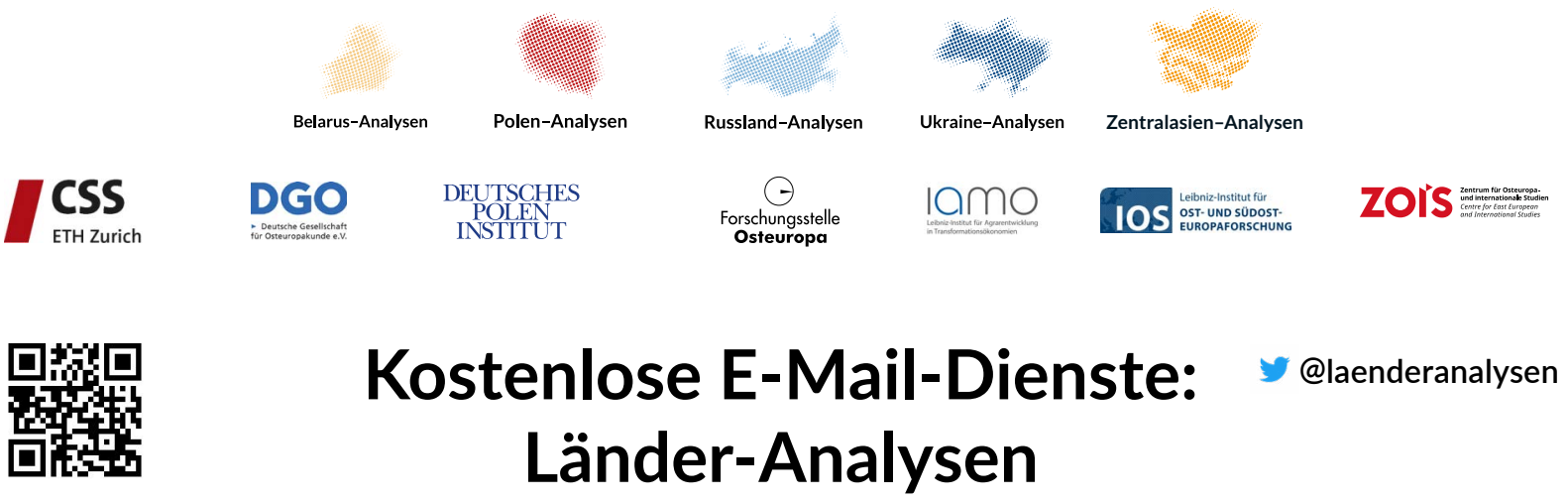

Die Länder-Analysen bieten regelmäßig im kostenlosen Abonnement kompetente Einschätzungen aktueller politischer, wirtschaftlicher, sozialer und kultureller Entwicklungen in Ostmitteleuropa und der GUS. Alle Länder-Analysen verstehen sich als Teil eines gemeinsamen Projektes, das der wissenschaftlich fundierten, allgemeinverständlich formulierten Analyse der Entwicklungen im östlichen Europa, der Offenheit für verschiedene inhaltliche Positionen und der kostenlosen und nicht-kommerziellen Information einer breit verstandenen interessierten Öffentlichkeit verpflichtet ist. Autor/innen sind internationale Fachwissenschaftler/innen und Expert/innen. Die Redaktionen der Länder-Analysen bestehen aus Wissenschaftler/innen mit langjähriger Forschungserfahrung.

Die deutschsprachigen Länder-Analysen werden gemeinsam von der Forschungsstelle Osteuropa an der Universität Bremen, dem Zentrum für Osteuropa- und internationale Studien, der Deutschen Gesellschaft für Osteuropakunde, dem Deutschen Polen-Institut, dem Leibniz-Institut für Agrarentwicklung in Transformationsökonomien und dem Leibniz-Institut für Ost- und Südosteuropaforschung herausgegeben. Die englischsprachigen Länder-Analysen erscheinen in Kooperation der Forschungsstelle Osteuropa mit dem Center for Security Studies (CSS) der ETH Zürich.

Die Länder-Analysen bieten regelmäßig Kurzanalysen zu aktuellen Themen, ergänzt um Grafiken und Tabellen sowie Dokumentationen. Zusätzlich gibt es eine Chronik aktueller Ereignisse.

\section{Belarus-Analysen}

Erscheinungsweise: zweimonatlich

Abonnement unter: http://www.laender-analysen.de/belarus/

\section{Caucasus Analytical Digest}

In englischer Sprache. Erscheinungsweise: zweimonatlich

Abonnement unter: http://www.css.ethz.ch/en/publications/cad.html

\section{Polen-Analysen}

Erscheinungsweise: zweimal monatlich

Abonnement unter: http://www.deutsches-polen-institut.de/newsletter/polen-analysen/

\section{Russland-Analysen}

Erscheinungsweise: zweimal monatlich

Abonnement unter: http://www.laender-analysen.de/russland/

\section{Russian Analytical Digest}

In englischer Sprache. Erscheinungsweise: zweimal monatlich Abonnement unter: http://www.css.ethz.ch/en/publications/rad.html

\section{Ukraine-Analysen}

Erscheinungsweise: zweimal monatlich

Abonnement unter: http://www.laender-analysen.de/ukraine/

\section{Zentralasien-Analysen}

Erscheinungsweise: zweimonatlich

Abonnement unter: http://www.laender-analysen.de/zentralasien/

TWITTER, TWEET, RETWEET und das Twitter Logo sind eingetragene Markenzeichen von Twitter, Inc. oder angeschlossenen Unternehmen. 